\title{
Cross-shore suspended sand and bed load transport on beaches
}

\author{
Nobuhisa Kobayashi, ${ }^{1}$ Andres Payo, ${ }^{1}$ and Lauren Schmied ${ }^{1}$ \\ Received 6 March 2007; revised 2 January 2008; accepted 27 February 2008; published 1 July 2008.
}

[1] Simple formulas are developed to predict the time-averaged rates of cross-shore suspended sand and bed load transport. The net suspended sand transport rate is expressed as the product of the depth-averaged current and the suspended sediment volume per unit bottom area with a reduction factor that accounts for the correlation between the timevarying fluid velocity and sediment concentration. The net bed load transport rate under nonlinear waves is assumed to be onshore and proportional to $\sigma_{U}^{3}$ where $\sigma_{U}$ is the standard deviation of the horizontal velocity. The probabilities of sediment movement and suspension are introduced to account for the initiation of sediment movement and suspension. Simple functions are proposed to account for the effects of a steep bottom slope on the bed load and suspended sediment transport rates. The proposed formulas are found to be in agreement with three data sets within a factor of about 2 . The proposed formulas are shown to be consistent with existing simple formulas. The formulas are incorporated into a time-averaged wave model and the continuity equation of bottom sediment to predict the beach profile evolution. The numerical model is compared with seven small-scale tests including berm erosion tests and seven large-scale tests including dune erosion tests. The numerical model predicts the overall beach profile evolution including the berm and dune erosion but does not always predict the fairly subtle profile changes including bar migration accurately.

Citation: Kobayashi, N., A. Payo, and L. Schmied (2008), Cross-shore suspended sand and bed load transport on beaches, J. Geophys. Res., 113, C07001, doi:10.1029/2007JC004203.

\section{Introduction}

[2] Cross-shore sediment transport on beaches has been investigated extensively [e.g., Nairn and Southgate, 1993; Kobayashi and Johnson, 2001; Dean and Dalrymple, 2002; van Rijn et al., 2003] but we still cannot predict beach profile evolution accurately, even for the idealized case of alongshore uniformity, normally incident waves, and uniform sediment. In order to improve our predictive capabilities, sediment transport models are becoming more sophisticated but less transparent. For example, Thornton et al. [1996] and Gallagher et al. [1998] used the energeticsbased total load model of Bailard [1981] to explain the offshore movement of a bar at Duck, North Carolina during storms. The onshore bar migration on the same beach was predicted by both Hoefel and Elgar [2003], using the skewed acceleration effect on bed load and Henderson et al. [2004], using a suspended sediment model. The roles of bed load and suspended load are not clear at present. An attempt is made here to synthesize and simplify existing cross-shore sediment transport models with the aim of developing a simple and robust model that is suited for

\footnotetext{
${ }^{1}$ Ocean Engineering Laboratory, Center for Applied Coastal Research, University of Delaware, Newark, Delaware, USA.

Copyright 2008 by the American Geophysical Union. 0148-0227/08/2007JC004203
}

engineering applications including the prediction of berm and dune erosion.

[3] This paper is a continuation of Kobayashi et al. [2005] who conducted small-scale tests on a fine sand beach and developed a numerical model for cross-shore suspended sediment transport. They obtained simple formulas for the offshore and onshore suspended sediment transport rates due to the undertow current and the correlation between the horizontal fluid velocity and suspended sediment concentration, respectively. The formulas are combined here to obtain a formula for the net rate of the suspended sediment transport which is directed offshore. This formula includes the probability of sediment suspension so that it may be applied to coarser sediments for which sediment suspension may be limited by their large settling velocities.

[4] The net bed load transport rate is predicted by a new formula. The probability of sediment movement is included so that this bed load formula may be applied to sediments that do not move continuously under wave action. This formula is similar to the sheet flow model by Trowbridge and Young [1989] which predicted the onshore movement of a bar observed during low-energy wave conditions at Duck, North Carolina. This formula is also shown to be consistent with the energetics-based bed load formula of Bagnold [1966] if the net bed load transport is assumed to be in the direction of wave propagation. The net cross-shore sediment transport rate is the sum of the net suspended 
sediment and bed load transport rates. The predicted net transport rate is shown to be in reasonable (within a factor of about 2) agreement with the water tunnel data of Ribberink and Al-Salem [1994] and Dohmen-Janssen et al. [2002] and the large-scale wave flume data of Dohmen-Janssen and Hanes [2002]. Furthermore, the proposed simple sediment model predicts the existence of equilibrium profiles [Dean, 1991] with additional assumptions.

[5] The proposed formulas for the net bed load and suspended sediment transport rates on a horizontal bottom or gentle slope are extended to a steep slope in order to predict berm and dune erosion. Simple bottom slope functions are proposed for the bed load transport rate on steep upward and downward slopes by modifying the functional form proposed by Bagnold [1966]. The net bed load transport on a steep upward slope is predicted to reverse its direction and become offshore. A simple algorithm is also proposed for the erosion of a scarped dune face.

[6] The proposed sediment model coupled with the conservation equation of bottom sediment is used to predict the evolution of a sand beach profile with and without a berm or dune. The predicted profile changes on the three equilibrium beaches in the small-scale experiment by Kobayashi et al. [2005] are shown to be fairly small. Erosion and accretion tests conducted in the same wave flume in this study are used to examine whether the sediment model can predict both beach erosion and accretion. The model is also compared with two berm erosion tests conducted in a wave basin. Finally, the sediment model is compared with the seven profile evolution tests with and without a dune in a large wave flume reported by Roelvink and Reniers [1995].

[7] This paper is organized as follows. Section 2 summarizes the numerical model and presents the formula for the net suspended sediment transport rate. Section 3 derives the formula for the net bed load transport rate and compares it with available formulas and data. Section 4 proposes simple functions to account for the effects of a steep bottom slope. Section 5 evaluates the sediment model with seven smallscale tests. Section 6 compares the model with seven largescale tests. Section 7 summarizes the findings of this study.

\section{Numerical Model and Suspended Sediment Formula}

[8] The numerical model described by Kobayashi et al. [2005] is used to predict the cross-shore variations of the variables involved in the sediment model developed in this study. The numerical model is summarized here to facilitate the subsequent derivation of the sediment model.

[9] The time-averaged cross-shore momentum and energy equations for normally incident random waves are expressed as

$$
\begin{gathered}
\frac{d S_{x x}}{d x}=-\rho g \bar{h} \frac{d \bar{\eta}}{d x}-\tau_{b} \\
\frac{d F}{d x}=-D_{B}-D_{f}
\end{gathered}
$$

where $x$ is the cross-shore coordinate, positive onshore, $S_{x x}$ is the cross-shore radiation stress, $\rho$ is the fluid density, $g$ is the gravitational acceleration, $\bar{h}$ is the mean water depth given by $\bar{h}=\left(\bar{\eta}-z_{b}\right)$ with $z_{b}$ being the bottom elevation, $\bar{\eta}$ is the mean free surface elevation, $\tau_{b}$ is the bottom shear stress, $F$ is the wave energy flux, and $D_{B}$ and $D_{f}$ are the energy dissipation rates due to wave breaking and bottom friction, respectively. Linear wave theory for onshore progressive waves is used to estimate $S_{x x}$ and $F$

$$
\begin{gathered}
S_{x x}=\rho g \sigma_{\eta}^{2}\left(\frac{2 C_{g}}{C_{p}}-\frac{1}{2}\right)+\rho C_{p} q_{r} \\
F=\rho g C_{g} \sigma_{\eta}^{2}
\end{gathered}
$$

where $\sigma_{\eta}$ is the standard deviation of the free surface elevation $\eta$ with the root-mean square wave height $H_{r m s}=$ $\sqrt{8} \sigma_{\eta}, C_{g}$ and $C_{p}$ are the group velocity and phase velocity in the mean water depth $\bar{h}$ corresponding to the spectral peak period $T_{p}$, and $q_{r}$ is the volume flux due to the roller on the steep front of a breaking wave. The equation for roller energy is expressed as

$$
\frac{d}{d x}\left(\rho C_{p}^{2} q_{r}\right)=D_{B}-D_{r}
$$

where the roller dissipation rate, $D_{r}=\rho g \beta_{r} q_{r}$, is assumed to equal the rate of work to maintain the roller on the wavefront slope $\beta_{r}$.

[10] Linear progressive wave theory based on the spectral peak period $T_{p}$ is used to estimate the standard deviation of the depth-averaged horizontal velocity $U$ as

$$
\sigma_{U}=C_{p} \sigma_{\eta} / \bar{h}
$$

which reduces to the equation used by Kobayashi et al. [2005] in shallow water. The depth-integrated continuity equation of water on the beach is used to estimate the depthaveraged return current

$$
\bar{U}=-g \sigma_{\eta}^{2} /\left(C_{p} \bar{h}\right)-q_{r} / \bar{h}
$$

where the onshore wave-induced volume flux is estimated as $g \sigma_{\eta}^{2} / C_{p}$ in finite depth.

[11] The time-averaged bottom shear stress and dissipation rate are expressed as

$$
\begin{aligned}
& \tau_{b}=\frac{1}{2} \rho f_{b} \overline{|U| U} \\
& D_{f}=\frac{1}{2} \rho f_{b} \mid \overline{\left.U\right|^{3}}
\end{aligned}
$$

where the overbar indicates time averaging, and $f_{b}$ is the bottom friction factor. The value of $f_{b}=0.015$ has been calibrated and used in the previous time-dependent computations for wave runup [Raubenheimer et al., 1995] and sand suspension [Kobayashi and Johnson, 2001; Kobayashi and Tega, 2002]. The computed results by this time-averaged model were found to be insensitive to $f_{b}$ by Kobayashi et al. [2005] and $f_{b}=0.015$ is used here as well. 
To express $\tau_{b}$ and $D_{f}$ in terms of $\bar{U}$ and $\sigma_{U}$, the equivalency of the time and probabilistic averaging as well as the Gaussian distribution of $U$ [Guza and Thornton, 1985; Kobayashi et al., 1998] are assumed.

$$
\begin{aligned}
& \tau_{b}=\frac{1}{2} \rho f_{b} \sigma_{U}^{2} G_{2}\left(U_{*}\right) \\
& D_{f}=\frac{1}{2} \rho f_{b} \sigma_{U}^{3} G_{3}\left(U_{*}\right)
\end{aligned}
$$

where $U_{*}=\bar{U} / \sigma_{U}$, and the analytical expressions of the functions $G_{2}(r)$ and $G_{3}(r)$ for an arbitrary variable $r$ were given by Kobayashi et al. [2005]. The functions $G_{2}$ and $G_{3}$ for the range $|r|<1$ can be approximated as $G_{2} \simeq 1.64 r$ and $G_{3} \simeq\left(1.6+2.6 r^{2}\right)$.

[12] The energy dissipation rate $D_{B}$ due to wave breaking in equation (2) is estimated using the formula by Battjes and Stive [1985], which was modified by Kobayashi et al. [2005] to account for the effect of the local bottom slope and to extend the computation to the lower swash zone. The bottom slope effect was also included in the roller slope $\beta_{r}$ which contributes to the roller energy dissipation rate $D_{r}$ in equation (5). The empirical adjustment of $\sigma_{*}=\sigma_{\eta} / \bar{h}$ proposed by Kobayashi et al. [2005] is not used for equations (6) and (7) to reduce the degree of empiricism. The breaker ratio parameter $\gamma$ in this formula is calibrated to obtain a good agreement for $\sigma_{\eta}$ for each test.

[13] Equations (1), (2), and (5) are solved using a finite difference method with constant grid spacing $\Delta x$ of the order of $1 \mathrm{~cm}$ and $5 \mathrm{~cm}$ for the following small-scale and large-scale tests, respectively. The bottom elevation $z_{b}(x)$ is known in the computation domain $x \geq 0$ where $x=0$ at the seaward boundary located outside the surf zone. The measured values of $T_{p}, \bar{\eta}, H_{r m s}=\sqrt{8} \sigma_{\eta}$ and $q_{r}=0$ at $x=0$ are specified as the seaward boundary conditions. The landward-marching computation is continued until the computed mean water depth $\bar{h}$ is practically zero. The computation is made with and without the roller effect, corresponding to IROLL $=1$ and 0 . For the option of IROLL $=0$, the roller volume flux $q_{r}=0$ and equation (5) is not used.

[14] After the landward-marching computation, the suspended sediment volume $V_{s}$ per unit area is estimated using the sediment suspension model by Kobayashi and Johnson [2001]

$$
V_{s}=\frac{e_{B} D_{B}+e_{f} D_{f}}{\rho g(s-1) w_{f}} P_{s}
$$

where $s$ and $w_{f}$ are the specific gravity and fall velocity of the sediment, $e_{B}$ and $e_{f}$ are the suspension efficiencies for $D_{B}$ and $D_{f}$, respectively, and $P_{s}$ is the probability of sediment suspension. The calibrated values by Kobayashi and Johnson [2001] are $e_{B}=0.005$ and $e_{f}=0.01$. When the roller effect is included, $D_{B}$ in equation (12) is replaced by the roller dissipation rate $D_{r}$ in equation (5). The sediment suspension probability $P_{s}$ is introduced here because $V_{s}=0$ if no sediment suspension occurs.

[15] Sediment suspension in the surf zone is intermittent, and individual suspension events are difficult to predict accurately [Kobayashi and Tega, 2002]. The probability $P_{s}$ representing the degree of sediment suspension may be estimated using the experimental finding of Kobayashi et al. [2005] who showed that the turbulent velocities measured in the vicinity of the bottom were related to the energy dissipation rate due to bottom friction and could be represented by $\left(D_{f}^{\prime} / \rho\right)^{1 / 3}$. The time-varying energy dissipation rate $D_{f}^{\prime}$ due to bottom friction is assumed to be given by equation (9) without the overbar. The probability $P_{S}$ is estimated as the probability of $\left(D_{f}^{\prime} / \rho\right)^{1 / 3}$ exceeding the sediment fall velocity $w_{f}$ where the probability distribution of the horizontal velocity $U$ is assumed to be Gaussian. This probabilistic analysis yields

$$
P_{s}=\frac{1}{2} \operatorname{erfc}\left(\frac{R_{s}+U_{*}}{\sqrt{2}}\right)+\frac{1}{2} \operatorname{erfc}\left(\frac{R_{s}-U_{*}}{\sqrt{2}}\right)
$$

where $\operatorname{erfc}$ is the complementary error function, $U_{*}=\bar{U} / \sigma_{U}$ and $R_{s}=\left[\left(2 / f_{b}\right)^{1 / 3} w_{f} / \sigma_{U}\right]$.

[16] Equation (13) does not account for the initiation of sediment movement. Sediment suspension occurs only after sediment movement is initiated. The time-varying bottom shear stress $\tau_{b}{ }^{\prime}$ is assumed to be given by equation (8) without the overbar. The sediment movement is assumed to occur when $\left|\tau_{b}{ }^{\prime}\right|$ exceeds the critical shear stress, $\rho g(s-1)$ $d_{50} \Psi_{c}$, where $d_{50}$ is the median diameter of the sediment and $\Psi_{c}$ is the critical Shields parameter taken as $\Psi_{c}=0.05$ [Madsen and Grant, 1976]. The probability of sediment movement based on the Gaussian distribution of $U$ is given by

$$
P_{b}=\frac{1}{2} \operatorname{erfc}\left(\frac{R_{b}+U_{*}}{\sqrt{2}}\right)+\frac{1}{2} \operatorname{erfc}\left(\frac{R_{b}-U_{*}}{\sqrt{2}}\right)
$$

where $R_{b}=\left[2 g(s-1) d_{50} \Psi_{c} f_{b}^{-1}\right]^{0.5} / \sigma_{U}$. Comparison of equations (13) and (14) indicates that $P_{s}>P_{b}$ if $R_{s}<R_{b}$. Use is made of $P_{s}=P_{b}$ if $R_{s}<R_{b}$. It is noted that the probabilities $P_{b}$ and $P_{s}$ are an easy way to include the initiation criteria for sediment movement and suspension in the sediment model, although these criteria are normally neglected for fine sands.

[17] Kobayashi et al. [2005] experimentally examined the onshore suspended sediment transport rate $q_{\text {on }}$ due to the correlation between the horizontal velocity and suspended sediment concentration as well as the offshore suspended sediment transport rate $q_{\text {off }}$ due to the undertow current. The volumetric transport rates per unit width were approximately expressed as $q_{\text {on }}=0.8 \sigma_{\eta} \sigma_{U} V_{s} / \bar{h}$ and $q_{\text {off }}=0.9(-\bar{U}) V_{s}$ where the return current $\bar{U}$ was negative (offshore) and $V_{s}$ was estimated using equation (12) with $P_{s}=1$. The net suspended sediment transport rate $q_{s}$ is given by $q_{s}=\left(q_{\text {on }}-q_{\text {off }}\right)$. Using equations (6) and (7) with $q_{r}=0$ and $C_{p}^{2}=g h$ for simplicity, $q_{s}$ is simply expressed as

$$
q_{s}=a \bar{U} V_{s}
$$

where the suspended load parameter $a$ is 0.1 for $P_{s}=1$. For the three small-scale equilibrium profile tests conducted by Kobayashi et al. [2005], the calculated values of $P_{s}$ using equation (13) are on the order of 0.7 , implying that $a=0.14$ if $P_{s}=0.7$. Since $a$ may have an uncertainty of a factor of about 2, $a=0.1$ and 0.2 have been tried. The computed 
results presented here are based on $a=0.2$, which gives better overall agreement for the tests with relatively small profile changes. The sensitivity to this parameter is discussed in relation to the subsequent berm and dune erosion tests. Equation (15) implies that the suspended sediment volume $V_{s}$ per unit bottom area is transported by the depth-averaged current $\bar{U}$ with the reduction factor $a$ which increases with the decrease of the positive correlation between the horizontal velocity and suspended sediment concentration.

[18] The bed load transport rate $q_{b}$ is discussed in the next section. The estimated total transport rate, $q=\left(q_{s}+q_{b}\right)$, is coupled with the continuity equation of bottom sediment

$$
\left(1-n_{p}\right) \frac{\partial z_{b}}{\partial t}+\frac{\partial q}{\partial x}=0
$$

where $n_{p}$ is the porosity of the bottom sediment, and $t$ is the morphological time for the change of the bottom elevation $z_{b}$. Equation (16) is solved using an explicit Lax-Wendroff numerical scheme [e.g., Nairn and Southgate, 1993; Tega and Kobayashi, 1999] to obtain the bottom elevation at the next time level. This computation procedure is repeated starting from the initial bottom profile until the end of each profile evolution test. The computation time is on the order of $10^{-3}$ of the test duration.

\section{Bed Load Formula}

[19] The time-averaged bed load transport rate $q_{b}$ derived from the quasi-steady application of the formula of Meyer-Peter and Mueller [e.g., Ribberink, 1998] is expressed as

$$
q_{b}=\alpha\left(\frac{f_{b}}{2}\right)^{1.5} \frac{P_{b}}{g(s-1)} \overline{U^{3}}
$$

where the coefficient $\alpha$ is approximately 10 , and the initiation of sediment movement is taken into account by the probability $P_{b}$ of sediment movement. The instantaneous bottom shear stress is assumed to be given by equation (8) without the overbar to obtain equation (17). Assuming the equivalency of the time and probabilistic averaging of $U^{3}$ in equation (17), $q_{b}$ is simplified as

$$
q_{b}=b P_{b} \sigma_{U}^{3} /[g(s-1)]
$$

where $b=\alpha b_{*}\left(f_{b} / 2\right)^{1.5}, b_{*}=\left(S_{U}+3 U_{*}+U_{*}^{3}\right), U_{*}=\bar{U} / \sigma_{U}$, and $S_{U}$ is the skewness of $U$. For the Gaussian distribution of $U$ with the mean $\bar{U}=0, S_{U}=0$ and $b_{*}=0$, resulting in $q_{b}=0$ as pointed out by Guza and Thornton [1985].

[20] The present numerical model predicts only $\bar{U}$ and $\sigma_{U}$ and an empirical formula [e.g., Doering et al., 2000] would be necessary to estimate $S_{U}$. The skewness $S_{U}$ cannot be predicted accurately at present. Furthermore, equation (17) does not include the effect of the fluid acceleration and pressure gradient [Hoefel and Elgar, 2003; Calantoni and Puleo, 2006; Foster et al., 2006], nor the effect of the onshore streaming and time-averaged bottom shear stress in the boundary layer [e.g., Rakha et al., 1997]. These effects cause onshore sediment transport. Bed forms including ripples are neglected partly because their geometry cannot be predicted accurately [e.g., Gallagher et al., 2003; Williams et al., 2005]. In view of the empirical nature of any sediment transport formula, it is desirable to develop a simple formula. Consequently, equation (18) with constant $b$ is tried, although it predicts only onshore bed load transport.

[21] The calibration of the bed load parameter $b$ in equation (18) is performed using the water tunnel data of Ribberink and Al-Salem [1994]. They presented the values of $\bar{U}$ and $\sigma_{U}$ measured at $20 \mathrm{~cm}$ above the bed, where $\sigma_{U}$ equals the root mean square velocity, for each of 20 tests in Series B. They used second-order Stokes wave theory to generate the horizontal velocity $U$ for regular and irregular waves. The median diameter and fall velocity of the quartz sand were $d_{50}=0.21 \mathrm{~mm}$ and $w_{f}=2.6 \mathrm{~cm} / \mathrm{s}$. The specific gravity is taken as $s=2.65$. The 20 tests included plane (sheet flow) and rippled beds. The net sediment transport rate obtained from the measured bed elevation change includes the suspended sediment transport rate $q_{s}$. Equations (15) and (18) are used to estimate $q_{s}$ and $q_{b}$ for each test where $V_{S}$ is predicted using equation (12) with $D_{B}=0$ for nonbreaking waves and $D_{f}$ given by equation (11). For the 20 tests, $-0.1<U_{*}<0.1$ and $G_{3}=1.6$ for irregular waves with weak currents. For regular waves, use is made of $G_{3}=|U|^{3} /$ $\sigma_{U}^{3}=1.2$ based on sinusoidal waves. In addition, use is made of the large-scale wave flume data of DohmenJanssen and Hanes [2002] who used regular nonbreaking waves. The same procedure is used to estimate $q_{s}$ and $q_{b}$ for each of the four sheet flow tests where $U_{*}=\bar{U} / \sigma_{U}$ was in the range of -0.076 to -0.056 , and the sand was characterized by $d_{50}=0.24 \mathrm{~mm}$ and $s=2.65$. The fall velocity of the sand is estimated as $w_{f}=3.2 \mathrm{~cm} / \mathrm{s}$ for a spherical particle [Trowbridge and Young, 1989].

[22] Figure 1 shows the calibration of the bed load parameter $b$ in equation (18) for the 24 tests where the results for each test tabulated in the report by Schmied et al. [2006a] exhibited no systematic variation of $b$ apart from the difference between the flume and tunnel data. For the calibrated value of $b=0.002$, the ratio $q_{s} / q_{b}$ is in the range of -0.022 to 0.017 and the measured sediment transport rate is assumed to be the same as the predicted bed load transport rate $q_{b}$. The predicted probabilities of sediment movement and suspension are the same or almost the same and in the range of 0.45 to 0.88 . The proposed simple formula predicts $q_{b}$ within a factor of about 2 . The increase of $b$ for the wave flume data may partly be attributed to the onshore streaming in the wave flume [Dohmen-Janssen and Hanes, 2002] but the choice of $b=0.002$ appears to be more consistent with other formulas as explained later. It is noted that no bed load data is presently available inside the surf zone perhaps because it is very difficult to separate bed load and suspended load.

[23] The net bed load transport rate $q_{b}$ predicted by equation (18) is in the direction of the nonlinear wave propagation. The problem with equation (18) is that it does not predict $q_{b}=0$ for sinusoidal waves. For sinusoidal waves with a current, equation (18) may be applicable if the direction of $q_{b}$ is assumed to be in the same direction as the current. To confirm this conjecture, comparison is made with the water tunnel data of Dohmen-Janssen et al. [2002] consisting of 24 sheet flow tests. The horizontal velocity $U$ 




Figure 1. Calibration of bed load parameter $b$ for volumetric bed load transport rate $q_{b}$ per unit width under nonbreaking, nonlinear waves in water tunnel and wave flume.

was varied with time $t$ in the form of $U=\left[\bar{U}+\sqrt{2} \sigma_{U} \cos \right.$ $(\omega t)]$ where $\omega$ is the angular frequency. The values of $\bar{U}$ and $\sqrt{2} \sigma_{U}$ for each test were tabulated. For the 24 tests, $U_{*}=$ $0.2-1.2$, indicating strong currents. The median diameters of the three sands used in the tests were $d_{50}=0.13,0.21$, and $0.32 \mathrm{~mm}$. The corresponding fall velocities were $w_{f}=$ $1.14,2.60$, and $4.29 \mathrm{~cm} / \mathrm{s}$. The specific gravity of these sands is taken as $s=2.65$. The values of $q_{s}$ and $q_{b}$ for each test are calculated in the same way except that $G_{3}=|U|^{3} / \sigma_{U}^{3}$ is computed numerically where $G_{3}=1.3-5.6$ for the 24 tests. For the sands with $d_{50}=0.13$ and $0.21 \mathrm{~mm}, P_{s}=P_{b}$, whereas for the sand with $d_{50}=0.32 \mathrm{~mm},\left(P_{b}-P_{s}\right)=0.02-$ 0.04 . For the 24 tests, $P_{b}=0.79-0.91, P_{s}=0.75-0.91$, and $q_{s} / q_{b}=0.06-1.47$. Figure 2 compares the measured transport rate $q_{m}$ with the predicted transport rate $q=\left(q_{s}+\right.$ $q_{b}$ ) for the 24 tests. The agreement is within a factor of about 2 for the three sands with no systematic variation among the 24 tests [Schmied et al., 2006a]. It is noted that $a=0.2$ in equation (15) accounts for the onshore suspended sediment transport rate due to the correlation between the horizontal velocity and concentration. The value of $a=0.2$ turns out to be acceptable in these tests perhaps because of time lags between the fluid velocity and concentration [Dohmen-Janssen et al., 2002].

[24] The present bed load formula is similar to the formula of Trowbridge and Young [1989] who assumed the proportionality between the net rate $q_{b}$ and the timeaveraged bottom shear stress $\tau_{b}$ and showed the proportionality between $\tau_{b}$ and the energy dissipation rate $D_{f}$ due to bottom friction. Their formula can be expressed in the form of equation (18) with the bed load parameter $b$ given by

$$
b P_{b}=\left(K f_{b} / 2\right) G_{3} w_{f} /(g \bar{h})^{0.5}
$$

where $K$ is an empirical parameter and the calibrated value of $\left(K f_{b}\right)$ was 0.5 . No current was taken into account in their formula and $G_{3}=1.6$ in equation (19). Their formula was used to explain the onshore bar migration outside the surf zone at Duck, North Carolina during the low-energy wave conditions between February and August 1982. The bar crest was located in the water depth $\bar{h} \simeq$ $3.5 \mathrm{~m}$, and the fall velocity of the $0.16-\mathrm{mm}$ sand was estimated as $w_{f}=1.8 \mathrm{~cm} / \mathrm{s}$. Substitution of these values into equation (19) yields $b P_{b}=0.0012$. The probability $P_{b}$ of sediment movement cannot be estimated from their data but might be assumed to be of the order of 0.5 outside the surf zone as will be presented later. As a result, their formula is consistent with equation (18) with $b$ of the order of 0.002 .

[25] The present bed load formula is also consistent with the energetics-based bed load formula by Bagnold [1966] for steady flow if the latter formula is applied in the following time-averaged manner instead of the time-varying application made by Bailard and Inman [1981]. The timeaveraged immersed weight bed load transport rate, $\rho g(s-1) q_{b}$, is assumed to be proportional to the time-averaged energy dissipation rate $D_{f}$ due to bottom friction where the energy dissipation rate $D_{B}$ due to wave breaking, included in equation (12), is neglected for the bed load. This relation 




Figure 2. Measured sediment transport rate $q_{m}$ compared with predicted total sediment transport rate, $q=\left(q_{b}+q_{s}\right)$, for combined sinusoidal wave-current sheet flow with median sediment diameters $d_{50}=$ $0.13,0.21$, and $0.32 \mathrm{~mm}$.

together with equation (11) results in equation (18) with the bed load parameter $b$ given by

$$
b P_{b}=\left(e_{b} / \tan \phi\right)\left(f_{b} / 2\right) G_{3}
$$

where $e_{b}$ is the bed load efficiency, and $\phi$ is the internal friction angle of the sediment. The adopted value of $\left(e_{b} / \tan \phi\right)$ was 0.18 by Bagnold [1966], 0.33 by Bailard and Inman [1981], 0.32 by Guza and Thornton [1985], and 0.21 by Thornton et al. [1996] and Gallagher et al. [1998]. Equation (20) yields $b P_{b}=0.0024$ for $\left(e_{b} / \tan \phi\right)=0.2, f_{b}=0.015$ and $G_{3}=1.6$. This value is twice as large as that based on equation (19).

[26] Finally, an equilibrium profile is derived from equation (15) for the offshore suspended sediment transport rate $q_{s}$ and equation (18) for the onshore bed load transport rate $q_{b}$ where $\left(q_{s}+q_{b}\right)=0$ for an equilibrium profile. Equation (12) is simplified by introducing $\left(e_{B} D_{B}+e_{f} D_{f}\right)=e_{c}\left(D_{B}+\right.$ $D_{f}$ ) where $e_{c}$ is a combined suspension efficiency. Then, the suspended sediment volume $V_{s}$ per unit area becomes proportional to the cross-shore gradient of the wave energy flux $F$ by use of equation (2). The approximations $C_{p}=C_{g}=$ $(g \bar{h})^{0.5}$ in shallow water and constant $\sigma_{*}=\sigma_{\eta} / \bar{h}$ in the surf zone are made for $F$ given by equation (4) to obtain a simple analytical solution. In addition, the probabilities $P_{b}$ and $P_{s}$ are assumed to be constant or the same. Using equations (6) and (7) with $q_{r}=0$, the condition of $\left(q_{s}+q_{b}\right)=0$ yields

$$
\begin{gathered}
\bar{h}=A\left(x_{s}-x\right)^{2 / 3} \\
A=\left(\frac{3 b P_{b}}{5 a P_{s} e_{c} \sigma_{*}}\right)^{2 / 3}\left(\frac{w_{f}^{2}}{g}\right)^{1 / 3}
\end{gathered}
$$

where $x_{s}$ is the cross-shore location of $\bar{h}=0$ and $\left(x_{s}-x\right)$ is the offshore distance from the shoreline. Equation (21) is the equilibrium profile popularized by Dean [1991] who presented an empirical relation between $A$ and $w_{f}$. Kriebel et al. [1991] approximated this empirical relation as $A=2.3 \beta$ for sands where $\beta=\left(w_{f}^{2} / g\right)^{1 / 3}$. Bowen [1980] derived $A=3.8$ $\beta$ analytically using a simple model. Equation (22) yields $A=2.4 \beta$ for $b / a=0.01, P_{s}=P_{b}, e_{c}=0.008$, and $\sigma_{*}=0.2$. These values may be regarded as typical inside the surf zone on sand beaches. However, the approximation of constant $\sigma_{*}$ is not accurate for barred beaches and near the shoreline.

\section{Bottom Slope Effects}

[27] The numerical model in section 2 coupled with the bed load formula given by equation (18) was found by Payo et al. [2006] to underpredict erosion of a steep berm on a sand beach. They neglected bed load and included only offshore suspended sediment transport to reproduce the observed berm erosion reasonably. This simplified approach is similar to that adopted by Steetzel [1991] to predict dune erosion during storm surge. The effect of a steep slope is added to the proposed formulas for bed load and suspended load to predict berm and dune erosion as well as beach profile evolution with minor changes.

[28] Equation (18) for the onshore bed load transport rate $q_{b}$ is modified as

$$
q_{b}=b P_{b} G_{s} \sigma_{U}^{3} /[g(s-1)]
$$

where the bottom slope function $G_{S}$ is unity on a horizontal bottom and assumed to depend on the local bottom slope 
Table 1. Offshore Wave Conditions for Five Small-Scale Tests

\begin{tabular}{lccccc}
\hline Test & $t_{b}, \mathrm{~s}$ & $d, \mathrm{~cm}$ & $\bar{\eta}, \mathrm{cm}$ & $T_{p}, \mathrm{~s}$ & $H_{r m s}, \mathrm{~cm}$ \\
\hline 4.8 & 900 & 80.6 & -0.10 & 4.8 & 11.5 \\
1.6 & 300 & 57.0 & -0.13 & 1.6 & 11.7 \\
2.6 & 400 & 71.4 & -0.15 & 2.6 & 13.0 \\
E & 400 & 76.0 & -0.16 & 2.6 & 12.8 \\
A & 400 & 77.2 & -0.07 & 2.7 & 8.1 \\
\hline
\end{tabular}

$S_{b}=\partial z_{b} / \partial x$ which is positive for an upward slope in the landward direction. The functional form of $G_{s}$ used by Bagnold [1966] for steady streamflow corresponds to $G_{s}=$ $\tan \phi /\left(\tan \phi+S_{b}\right)$ where $\phi$ is the angle of internal friction of the sediment and $\tan \phi \simeq 0.63$ for sand [Bailard, 1981]. Bailard and Inman [1981] modified this functional form for oscillatory flow on a gentle slope with $\left|S_{b}\right| \ll \tan \phi$. This assumption is normally valid for a sand beach in the absence of berm or dune erosion. The slope effect on the cross-shore sand transport is secondary as long as $\left|S_{b}\right| \ll$ $\tan \phi$.

[29] The bottom slope function $G_{s}$ is empirically expressed as

$$
\begin{gathered}
G_{s}=\tan \phi /\left(\tan \phi+S_{b}\right) \quad \text { for } \quad-\tan \phi<S_{b}<0 \\
G_{s}=\left(\tan \phi-2 S_{b}\right) /\left(\tan \phi-S_{b}\right) \quad \text { for } \quad 0<S_{b}<\tan \phi
\end{gathered}
$$

where $G_{s}>1$ for $S_{b}<0$ and $G_{s}<1$ for $S_{b}>0$. The downward (upward) slope increases (decreases) the onshore bed load transport rate $q_{b}$ given by equation (23). Equations (24) and (25) yield $G_{s} \simeq\left(1-S_{b} / \tan \phi\right)$ for $\left|S_{b}\right| \ll$ $\tan \phi$ and $G_{s}$ approaches a positive (negative) infinity as the slope $S_{b}$ approaches $-\tan \phi(\tan \phi)$. These asymptotic characteristics of $G_{s}$ appear physically realistic. For the following computation, use is made of $\left|G_{s}\right|<G_{m}=10$ where the computed profile evolution is found to be insensitive to the imposed value of $G_{m}=2-100$. Furthermore, equation (25) gives $G_{s}<0$ for $S_{b}>(\tan \phi) / 2$, implying that the time-averaged bed load transport rate $q_{b}$ is negative (offshore) on an upward slope with $S_{b}>0.315$ for the adopted value of $\tan \phi=0.63$. The slope of $S_{b} \simeq 0.3$ seems reasonable in light of the downward dislodgement of stone on the slope $S_{b}=0.5$ under wave action [Melby and Kobayashi, 1998]. However, equations (24) and (25) depend on the relative slope $S_{b} / \tan \phi$ only and do not account for the flow characteristics on the slope. No suitable data may be available for the assessment of these empirical equations.

[30] The effect of the bottom slope on suspended sediment transport was examined by Bailard [1981] and Guza and Thornton [1985]. The bottom slope effect on the suspended sediment transport rate is expected to be small because suspended sediment particles are not in contact with the bottom. The suspended sediment volume $V_{s}$ per unit horizontal area given by equation (12) depends on the wave energy dissipation rates $D_{B}$ and $D_{f}$ computed on the actual bottom profile. The effect of the bottom slope may simply be included as the actual bottom area $\left(1+S_{b}^{2}\right)^{0.5}$ exposed to wave action per unit horizontal area. The suspended sediment transport rate $q_{s}$ given by equation (15) for an essentially horizontal bottom is modified as

$$
q_{s}=a \bar{U} V_{s}\left(1+S_{b}^{2}\right)^{0.5}
$$

where $q_{s}$ is in the direction of the current $\bar{U}$.

[31] The continuity equation (16) of bottom sediment together with equations (23) and (26) is solved numerically to predict the temporal change of the bottom elevation $z_{b}$ in the subsequent comparisons. The present time-averaged model is limited to the region of the mean water depth $\bar{h}$ $\geq h_{m}$ where $h_{m}$ is the smallest mean water depth at $x=x_{m}$ corresponding to the last node of the landward marching computation and of the order of $0.2 \mathrm{~cm}$ and $1 \mathrm{~cm}$ for the following small-scale and large-scale tests, respectively. This time-averaged model does not predict erosion of a steep dune face if the slope is exposed to occasional wave runup only. The computed total sediment transport rate $q_{m}$ at $x=x_{m}$ is extrapolated linearly to estimate $q$ on the scarped face with $S_{b}>\tan \phi$ if $q_{m}<0$

$$
q=q_{m}\left(x_{e}-x\right) /\left(x_{e}-x_{m}\right) \quad \text { for } \quad x_{m}<x<x_{e}
$$

where $x_{e}$ is the landward limit of $S_{b}>\tan \phi$. The condition of $q_{m}<0$ is necessary to ensure the offshore transport of sediment eroded from the steep face. Substitution of equation (27) into equation (16) yields

$$
\left(1-n_{p}\right) \frac{\partial z_{b}}{\partial t}=\frac{q_{m}}{x_{e}-x_{m}} \quad \text { for } \quad x_{m}<x<x_{e}
$$

which implies that the vertical erosion rate is uniform on the steep face if $q_{m}<0$.

[32] In the following, the numerical model in section 2 coupled with the sediment transport formulas given by equations (23)-(27) is compared with 14 small-scale and large-scale tests. The empirical parameters in the coupled model are kept constant for these 14 tests except for the breaker ratio parameter $\gamma$ related to the cross-shore variation of the free surface standard deviation $\sigma_{\eta}$.

\section{Comparison With Small-Scale Tests}

[33] Kobayashi et al. [2005] conducted three small-scale equilibrium profile tests in a wave flume that was $30 \mathrm{~m}$ long, $1.15 \mathrm{~m}$ wide, and $1.5 \mathrm{~m}$ high. Table 1 lists the offshore wave conditions measured by the most seaward wave gauge 1 for the three tests identified by the corresponding spectral peak periods $T_{p}$ where $t_{b}$ is the duration of the irregular waves generated in a burst, and $d, \bar{\eta}$ and $H_{\text {rms }}$ are the still water depth, wave setdown, and root-mean square wave height at wave gauge 1 . Figure 3 shows the three equilibrium profiles produced by the irregular waves with the different spectral peak periods. It is noted that equation (21) does not account for the wave period and that the outer (shorerise) portion of the profile needs to be treated separately [Inman et al., 1993]. The sand was characterized by $d_{50}=0.18 \mathrm{~mm}, s=2.6, w_{f}=2.0 \mathrm{~cm} / \mathrm{s}$, and $n_{p}=0.4$. Each test is computed using the measured equilibrium profile as the initial profile under the constant wave conditions given in Table 1. Kobayashi et al. [2005] already compared the 

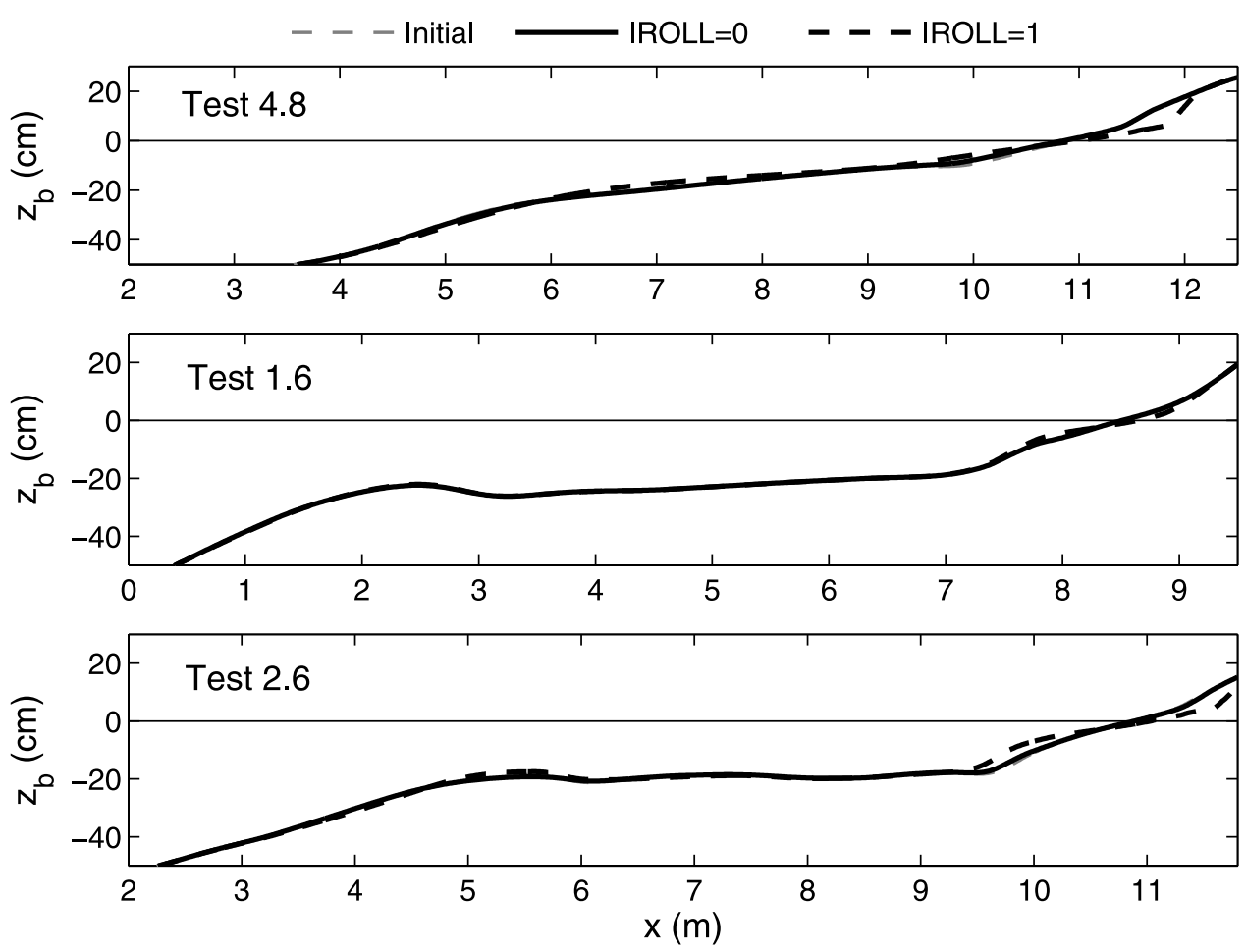

Figure 3. Predicted beach profile changes after 20 bursts for equilibrium profile tests (top) 4.8 , (middle) 1.6, and (bottom) 2.6 where IROLL $=1$ and 0 indicate the computed results with and without the roller volume flux $q_{r}$.

measured and predicted cross-shore variations of $\bar{\eta}, \sigma_{\eta}, \bar{U}$, $\sigma_{U}$ and $V_{s}$ for these tests. The breaker ratio parameter $\gamma$ was calibrated to be 0.6 for tests 4.8 and 1.6 and 0.8 for test 2.6. The present computation for the profile evolution is performed for a duration of 20 bursts because the measured bottom elevation change was less than $1 \mathrm{~cm}$ after 20 bursts.

[34] The predicted beach profiles after 20 bursts for the three tests are shown in Figure 3 where computation is made with and without the roller volume flux $q_{r}$ which increases the offshore return current and suspended sediment transport rate. The difference between the predicted and equilibrium profiles is larger for IROLL $=1$ with the roller and increases with the spectral peak period $T_{p}=1.6,2.6$, and 4.8. The equilibrium profile for test 1.6 is predicted satisfactorily for both IROLL $=0$ and 1 where the predicted profile change is less than $2 \mathrm{~cm}$. For tests 2.6 and 4.8 , IROLL $=1$ predicts vertical accretion of more than $5 \mathrm{~cm}$ slightly below the still water level (SWL) and vertical erosion of more than $5 \mathrm{~cm}$ above SWL. It is difficult to predict the three equilibrium profiles using the suspended sediment and bed load formulas given by equations (23) and (26) with $a=0.2$ and $b=0.002$. In reality, $a$ and $b$ are expected to vary in the cross-shore by a factor of about 2 .

[35] Erosion and accretion tests were conducted in the same wave flume. The equilibrium profile of test 2.6 existed in the wave flume after the completion of tests $4.8,1.6$, and 2.6 conducted in sequence. For the erosion test, the foreshore of the equilibrium beach was nourished using the same sand used for the three tests. The height and crossshore width of the nourished sand were approximately $0.3 \mathrm{~m}$ and $0.8 \mathrm{~m}$, respectively. The irregular waves used for test 2.6 were generated in a burst of $400 \mathrm{~s}$ by a piston-type wave paddle. The initial profile of the erosion test was taken as the profile measured after the first burst to reduce the artificiality of the sand nourishment. The initial profile was exposed to 23 bursts during the erosion test. For the accretion test, the root mean square wave height, $H_{r m s}=$ $\sqrt{8} \sigma_{\eta}$, was reduced by $37 \%$ and the beach was exposed to 20 bursts.

[36] The instruments used for the erosion and accretion tests were the same as those for the three previous tests described by Kobayashi et al. [2005]. Eight wave gauges were used to measure the time series of the free surface elevation from outside the surf zone to the swash zone. Two acoustic-Doppler velocimeters were used to measure the velocities at two locations. A fiber optic sediment monitor with two sensors was used to measure the sand concentrations at two locations. Beach profiles along three crossshore transects were measured after 1, 2, 3, 6, 10, 14, 19, and 23 bursts for the erosion test and after 2, 4, 7, 11, 15, and 20 bursts for the accretion test. The data and comparison with the numerical model were presented in the report by Schmied et al. [2006a].

[37] Table 1 lists the wave conditions at the offshore wave gauge 1 for the erosion (E) and accretion (A) tests. The value of $\gamma=0.8$ calibrated for test 2.6 is used for tests $E$ and A. The measured and predicted cross-shore variations of $\bar{\eta}$, $\sigma_{\eta}, \bar{U}, \sigma_{U}$ and $V_{s}$ were compared in the same way as described by Kobayashi et al. [2005] for tests 4.8, 1.6 and 2.6. The degree of agreement was similar as presented by Schmied et al. [2006b].

[38] Figure 4 shows the measured initial and final profiles and predicted final profiles for tests $\mathrm{E}$ and $\mathrm{A}$. For test $\mathrm{E}$, the lower swash zone and the bar trough were eroded, whereas 


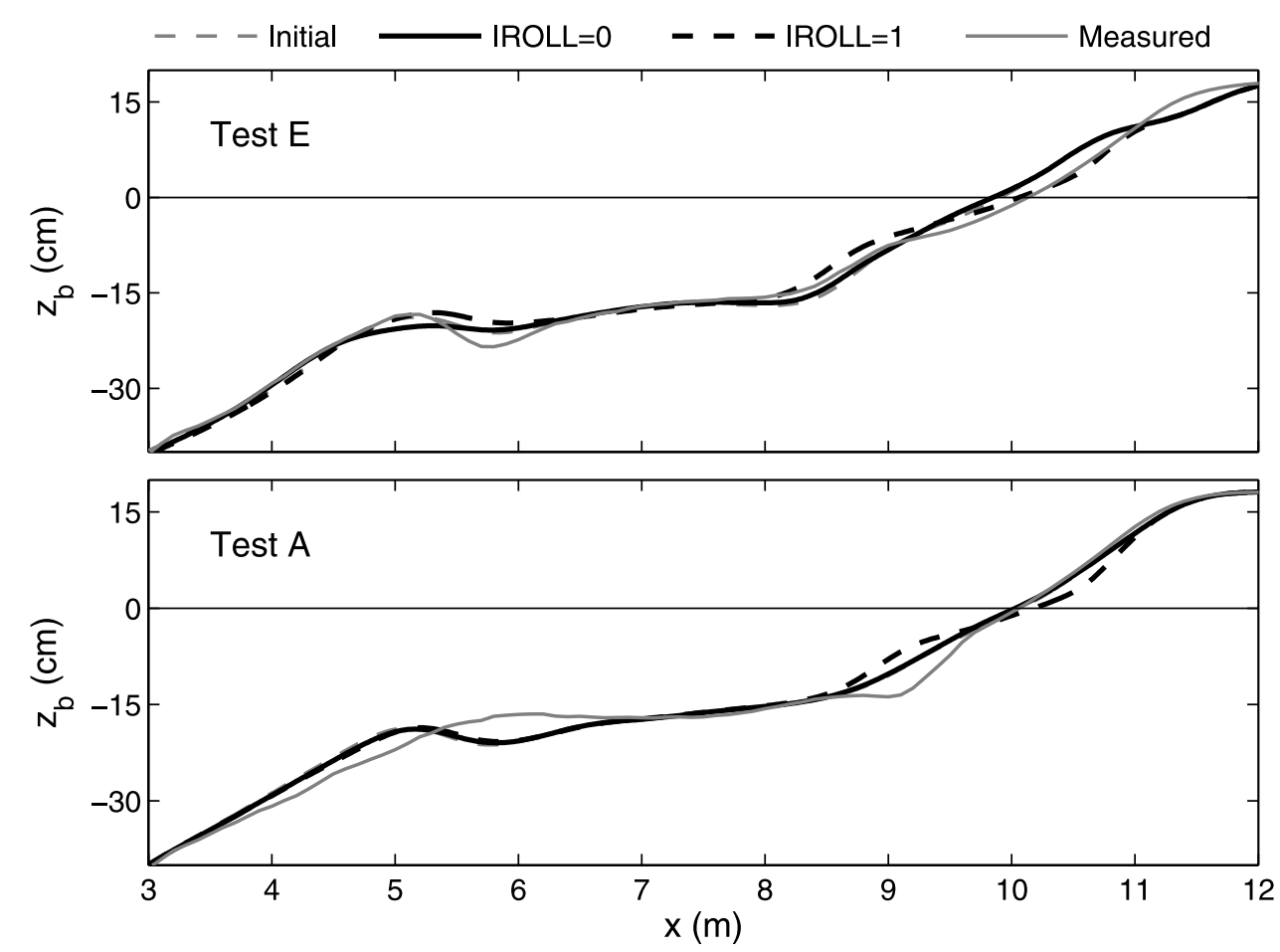

Figure 4. Measured and predicted beach profile changes for (top) erosion test after 23 bursts, and (bottom) accretion test after 20 bursts.

the upper swash zone and the transition zone between the surf and swash zones were accreted. The vertical elevation change was less than $3 \mathrm{~cm}$. The initial profile measured after one 400-s burst of waves on the nourished beach turned out to be fairly stable. The numerical model with IROLL $=1$ predicts the profile change near the shoreline better but both IROLL $=0$ and 1 cannot predict the bar trough erosion. For test A, the bar moved onshore and the zone below SWL was eroded. The vertical elevation change was less than $5 \mathrm{~cm}$. The numerical model with IROLL $=0$ and 1 underpredicts the onshore bar migration considerably and predicts slight accretion in the erosion zone below SWL.

[39] van Rijn et al. [2003] used the Brier Skill Score (BSS) to quantify the degree of agreement between the measured and predicted bars for existing five profile models. The BSS compares the mean square difference between the computed and measured bottom elevations with the mean square difference between the initial and measured elevations. The BSS is one for perfect agreement and zero if the computed and initial profiles are the same. The BSS does not consider the migration direction of a bar and is very sensitive if the difference between the initial and measured elevations is small. The BSS is calculated for the compared profiles in Figure 4 and subsequent figures. The BSS is noisy in the zones of small profile changes but is useful in identifying the zones of relatively large profile changes and poor agreements such as the zone of the bar migration in Figure 4. In these zones, the BSS is less than 0.5 . The present profile model based on linear wave theory and constant $a$ and $b$ cannot predict the bar migration unlike the profile models evaluated by van Rijn et al. [2003].

[40] Figure 5 shows the predicted cross-shore variations of the probabilities $P_{b}$ and $P_{s}$ and the sediment transport rates $q_{s}, q_{b}$ and $q=\left(q_{b}+q_{s}\right)$ for test $\mathrm{E}$ as an example. For the five small-scale tests in Table $1, P_{s}=P_{b}$ and the suspension of the fine sand with $d_{50}=0.18 \mathrm{~mm}$ occurs when its movement is initiated in these tests. The probabilities $P_{b}$ and $P_{s}$ increase onshore outside the surf zone, and reach approximately 0.7 in the outer surf zone and 0.8 in the swash zone. The offshore suspended sediment transport rate $q_{s}$ is very small outside the surf zones, increases in the breaker zone, and decreases onshore except for the second peak near the still water shoreline due to wave breaking in the small water depth [Puleo et al., 2000]. The cross-shore variation of the onshore bed load transport rate $q_{b}$ is similar to that of $\left(-q_{s}\right)$ except that the offshore decrease of $q_{b}$ is more gradual. The net transport rate $q$ is on the order of $0.01 \mathrm{~cm}^{2} / \mathrm{s}$ and very small in comparison to the measured values plotted in Figures 1 and 2. The difference between IROLL $=0$ and 1 becomes more apparent in the small net rate $q$.

[41] In the following, the numerical model is compared with the two berm erosion tests presented by Payo et al. [2006]. These tests were conducted in a wave basin that was $18 \mathrm{~m}$ long, $18 \mathrm{~m}$ wide, and $1.1 \mathrm{~m}$ high. Well-sorted sand was placed on a concrete slope of 0.05 . The sand was characterized by $d_{50}=0.19 \mathrm{~mm}, s=2.65, w_{f}=2.2 \mathrm{~cm} / \mathrm{s}$, and $n_{p}=0.4$. Flap-type wave paddles were used to generate normally incident irregular waves, based on the TMA spectrum. Five wave gauges were used to measure the time series of the free surface elevation. Two tests were conducted on a $0.6-\mathrm{m}$ wide berm backed by a dune with a seaward berm slope of approximately $1 / 4$ as shown in Figure 6. One berm was horizontal and the other berm was tilted landward with a slope of approximately 0.03 to reduce wave overtopping of the berm and examine the effect of ponding on berm erosion in light of the erosion 


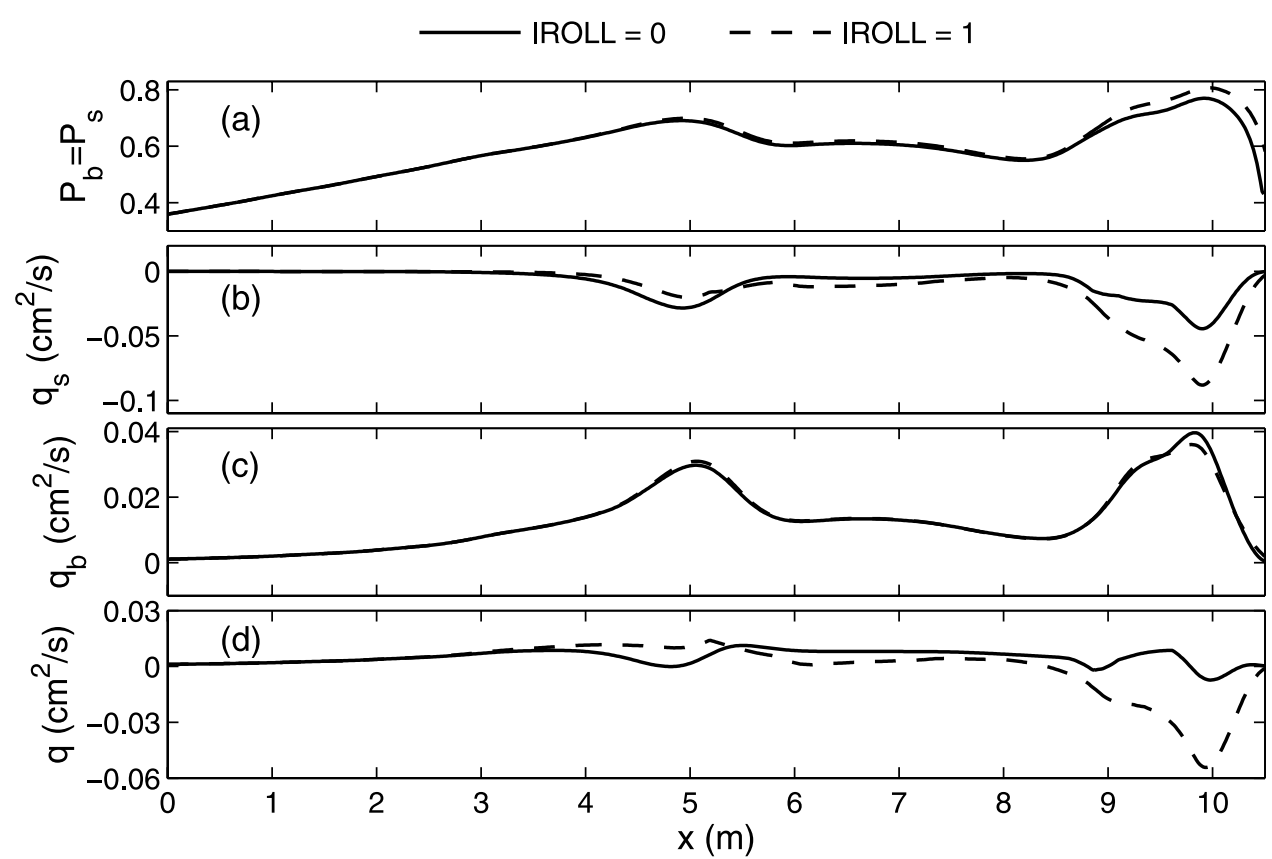

Figure 5. Predicted cross-shore variations for erosion test of (a) sediment movement probability $P_{b}$, where sediment suspension probability $P_{s}=P_{b}$ for this test; (b) volumetric suspended sediment transport rate $q_{s}$ per unit width; (c) bed load transport rate $q_{b}$; and (d) total sediment transport rate, $q=\left(q_{s}+q_{b}\right)$.

pattern of a southern California beach fill observed by Seymour et al. [2005]. The berm and dune profile of alongshore uniformity was built carefully, but small alongshore irregularities were discernible.
[42] Table 2 lists the depth and wave conditions at the offshore wave gauge for the flat and tilted berm tests. The wave height $H_{\mathrm{rms}}$ and period $T_{p}$ were about $5 \mathrm{~cm}$ and $1.1 \mathrm{~s}$, respectively. Four still water levels in the wave basin were

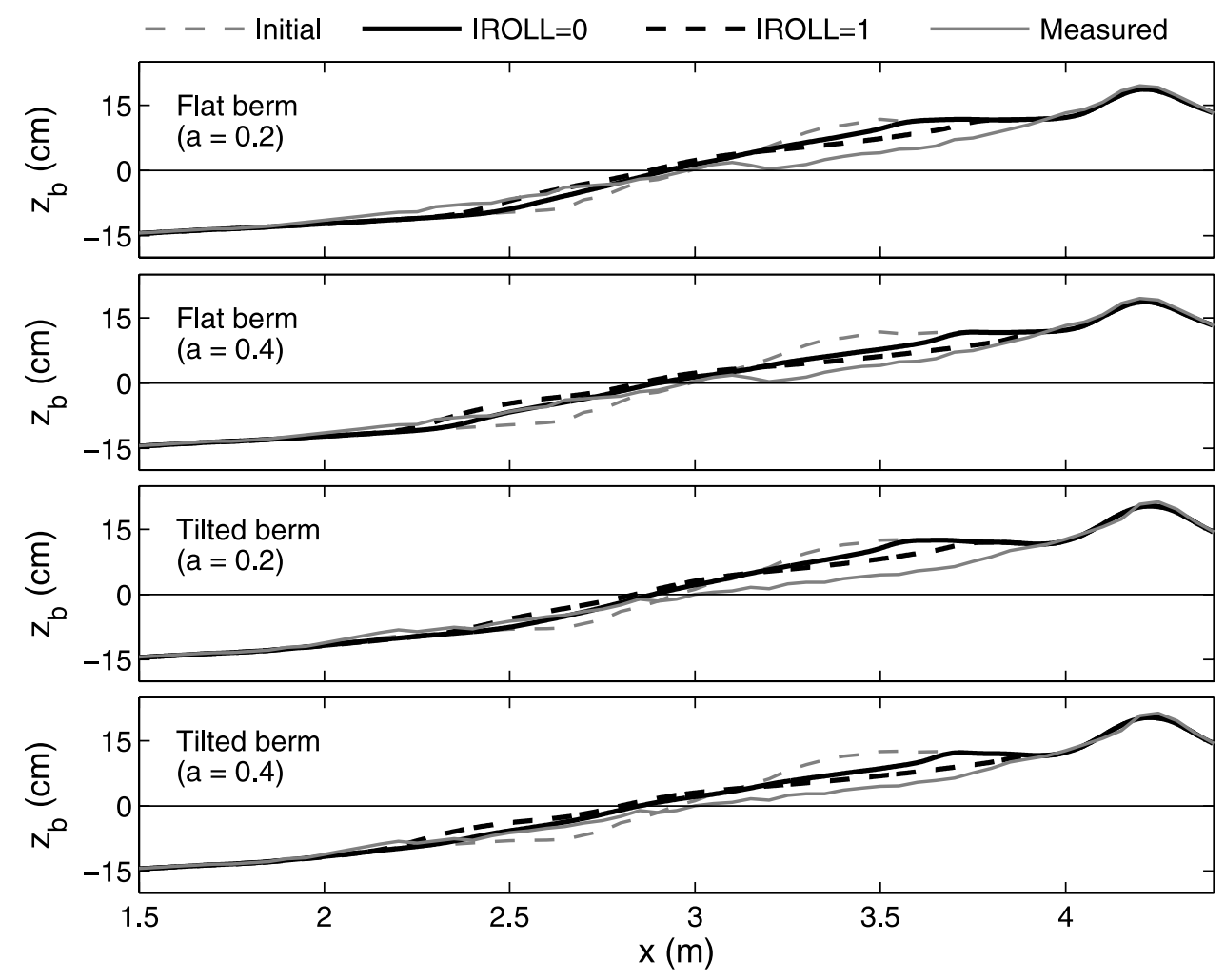

Figure 6. Measured and predicted profile changes at the end of (top two) the flat berm test, and (bottom two) tilted berm test for suspended load parameter $a=0.2$ and 0.4 . 
Table 2. Offshore Wave Conditions for Two Berm Erosion Tests

\begin{tabular}{lcccc}
\hline Berm & $t_{d}, \min$ & $d, \mathrm{~cm}$ & $T_{p}, \mathrm{~s}$ & $H_{\mathrm{rms}}, \mathrm{cm}$ \\
\hline Flat & 143 & 22.0 & 1.07 & 4.6 \\
& 15 & 25.3 & 1.07 & 5.0 \\
& 30 & 27.4 & 1.09 & 5.3 \\
\multirow{4}{*}{ Tilted } & 25 & 29.8 & 1.09 & 5.6 \\
& 143 & 22.0 & 1.10 & 4.5 \\
& 15 & 26.0 & 1.12 & 5.0 \\
& 30 & 27.5 & 1.12 & 5.2 \\
& 25 & 30.4 & 1.11 & 5.6 \\
\hline
\end{tabular}

used for each test to produce the sequence of foreshore erosion, berm overwash, berm erosion, and minor dune overtopping. The test was terminated when the berm erosion reached the toe of the dune. The duration $t_{d}$ of wave action for each water level is shown in Table 2. Erosion was relatively rapid after the berm was overwashed. Wave overtopping of the tilted berm resulted in ponding on the berm and return flow through narrow channels. This threedimensional berm erosion pattern was ephemeral and disappeared when the seaward edge of the tilted berm was eroded.

[43] The beach profile from the offshore wave gauge location to the landward edge of the dune was measured only in the middle of the wave basin because the berm erosion appeared to be uniform alongshore apart from the ephemeral three-dimensional pattern. The beach profile was measured at the start and end of each test and when the still water level was increased. The measured profiles were presented by Payo et al. [2006]. The difference between the flat and tilted berm tests was surprisingly small, indicating that the ponding effect on the subsequent berm erosion was small. The problem of alongshore nonuniformity was discovered during the data analysis after the sand was removed from the wave basin. The ratio between the accreted and eroded areas fluctuated with time and the average ratio was about 0.3 . The sand along this crossshore line was lost alongshore due to unknown causes as may be discernible by comparing the measured final and initial profiles in Figure 6. These limited tests suggest that the assumption of alongshore uniformity may be valid only for two-dimensional experiments in narrow wave flumes.

[44] Figure 6 compares the measured and predicted profiles at the end of the flat and tilted berm tests. Use is made of the breaker ratio parameter $\gamma=1$ on the relatively steep berm slope [Payo et al., 2006]. The berm erosion is predicted better for IROLL $=1$ because the roller increases the offshore return current and suspended sediment transport rate in shallow water as shown in Figure 5. The predicted profiles for the suspended load parameter $a=$ 0.2 and 0.4 in equation (26) are presented to show the sensitivity to this empirical parameter with its uncertainty of a factor of about 2 . The computed cross-shore variations of $P_{s}, P_{b}, q_{s}, q_{b}$ and $q=\left(q_{s}+q_{b}\right)$ plotted (not shown) in the same way as in Figure 5 indicate that the sand movement, suspension and transport in these very small-scale tests occur mostly on the berm itself. The value of $a=0.4$ predicts the berm erosion better but some of the berm erosion was caused by the gradient of the longshore sand transport on the berm. The value of $a$ cannot be calibrated using the data affected by the alongshore variability.

\section{Comparison With Large-Scale Tests}

[45] The numerical model is compared with the seven large-scale tests reported by Roelvink and Reniers [1995]. These tests listed in Table 3 were conducted in a wave tank that was $233 \mathrm{~m}$ long, $5 \mathrm{~m}$ wide, and $7 \mathrm{~m}$ deep. Tests $1 \mathrm{a}, 1 \mathrm{~b}$, and $1 \mathrm{c}$ with no dune are discussed together before tests $2 \mathrm{a}$, $2 \mathrm{~b}, 2 \mathrm{e}$, and $2 \mathrm{c}$ with a dune. Figure 7 shows the measured initial and final profiles in the region of the noticeable profile changes for tests $1 \mathrm{a}, 1 \mathrm{~b}$, and $1 \mathrm{c}$ performed in sequence. The profile changes were relatively small and will later be discussed in detail. The initial profile for test 1a was based on the equilibrium profile given by equation (21) with $A=0.1 \mathrm{~m}^{1 / 3}$ and no wave setup which was connected to a uniform slope near the shoreline. The median diameter of the sand in the tank was $d_{50}=0.2 \mathrm{~mm}$. The specific gravity and porosity are assumed as $s=2.65$ and $n_{p}=0.4$. The estimated fall velocity for the corresponding sphere is $w_{f}=2.3 \mathrm{~cm} / \mathrm{s}$. The duration $t_{t}$ in hours of each test is listed in Table 3 which also presents the average wave conditions in the still water depth $d \simeq 4 \mathrm{~m}$ at the toe of the beach located at $x=0$ in Figure 7. The wave conditions measured hourly varied somewhat and the measured values of $\bar{\eta}, T_{p}$ and $H_{r m s}$ at $x=0$ are used as input in the following computations.

[46] The measured and predicted cross-shore variations of $\bar{\eta}, \sigma_{\eta}, \bar{U}, \sigma_{U}$ and $V_{s}$ were compared and presented in the report of Schmied et al. [2006a]. The values of $\gamma=0.6,0.7$, and 0.8 were tried and the best agreement for $\sigma_{\eta}$ was obtained for $\gamma=0.7$ which is used for all the seven tests. The agreement for the large-scale tests is found to be similar to that for the small-scale tests presented by Kobayashi et al. [2005]. The comparisons using $\gamma=0.7$ are presented for test $1 \mathrm{c}$ as an example. In the following, the hourly comparisons are condensed by plotting the average of the predicted cross-shore variations for the entire test duration where the deviation among the hourly predicted values is smaller than the disagreement between the measured and predicted values.

[47] Figure 8 shows the comparisons for the mean and standard deviation of the free surface elevation $\eta$. The crossshore locations of the two kinks in the predicted $\bar{\eta}$ and $\sigma_{\eta}$ correspond to the locations of the bar crest and terrace edge of the beach profile for test $1 \mathrm{c}$ shown in Figure 7. The agreement is very similar for IROLL $=0$ and 1 .

[48] Figure 9 shows the comparisons of the mean and standard deviation of the horizontal velocity $U$. The horizontal velocities were measured at $0.1,0.2,0.4,0.7$, and 1.1 $\mathrm{m}$ above the local bed. The measured mean velocities at the

Table 3. Offshore Wave Conditions for Seven Large-Scale Tests

\begin{tabular}{cccccc}
\hline Test & $t_{t}, \mathrm{~h}$ & $d, \mathrm{~cm}$ & $\bar{\eta}, \mathrm{cm}$ & $T_{p}, \mathrm{~s}$ & $H_{r m s}, \mathrm{~cm}$ \\
\hline 1a & 12 & 412 & -1.1 & 4.8 & 64 \\
1b & 18 & 406 & -3.3 & 5.0 & 93 \\
1c & 13 & 407 & -0.8 & 8.0 & 39 \\
2a & 9 & 403 & -1.9 & 5.0 & 62 \\
2b & 12 & 402 & -4.5 & 5.0 & 100 \\
2e & 18 & 454 & -3.1 & 5.0 & 101 \\
2c & 21 & 404 & -1.1 & 8.0 & 41 \\
\hline
\end{tabular}




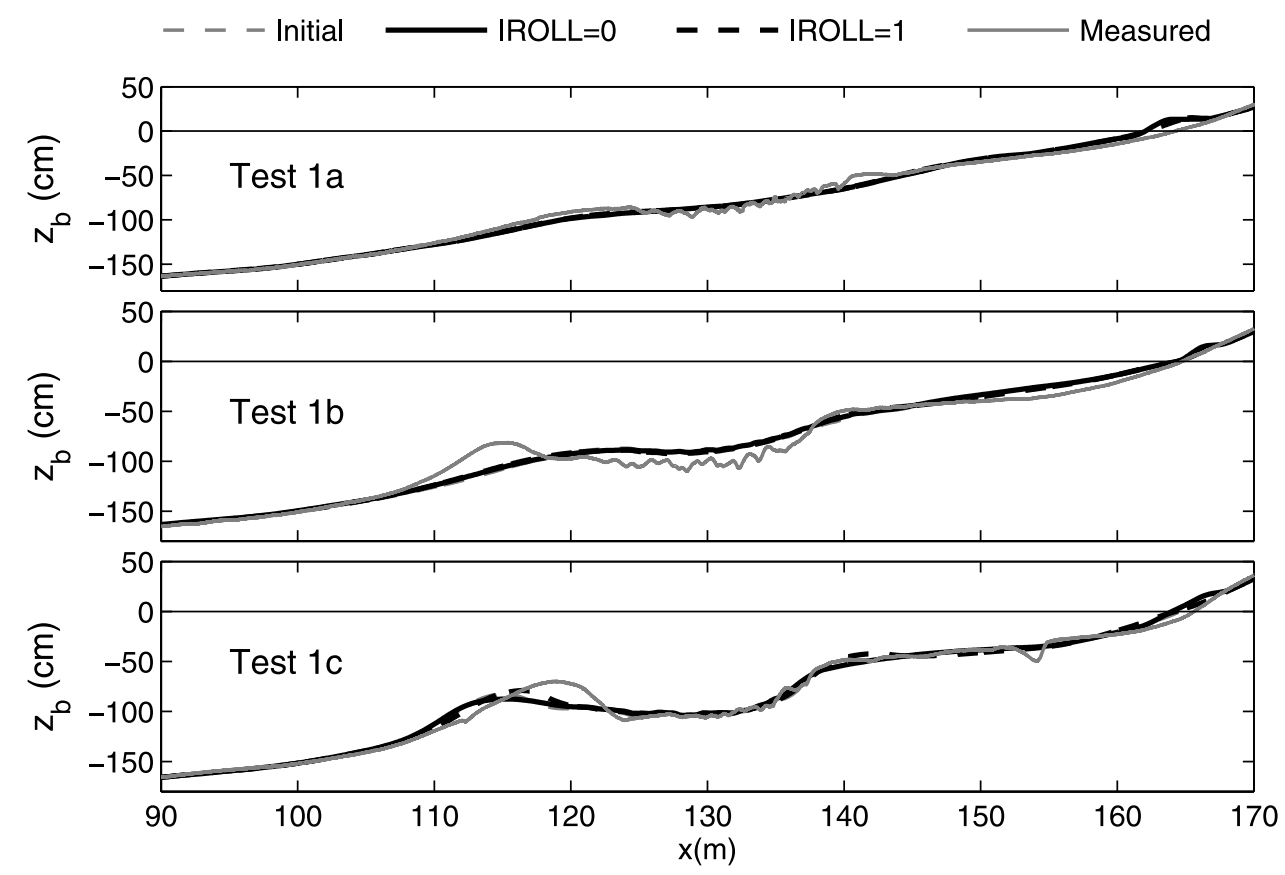

Figure 7. Measured and predicted beach profile changes at the end of large-scale tests (top) 1a, (middle) $1 \mathrm{~b}$, and (bottom) $1 \mathrm{c}$.

given cross-shore location were fitted by a parabolic undertow profile and the averaged velocity in the zone of the negative mean velocity was calculated as explained by Kobayashi et al. [2005]. This averaged velocity is plotted as the data point of $\bar{U}$. The data point of $\sigma_{U}$ in Figure 9 is the vertically averaged value of the measured standard deviations which varied little vertically. The numerical model with IROLL $=0$ and 1 cannot predict the cross-shore variation of $\bar{U}$ very accurately as was the case with the previous comparison by Kobayashi et al. [2005]. The waveinduced volume flux based on linear wave theory in equation (7) may need to be improved for nonlinear
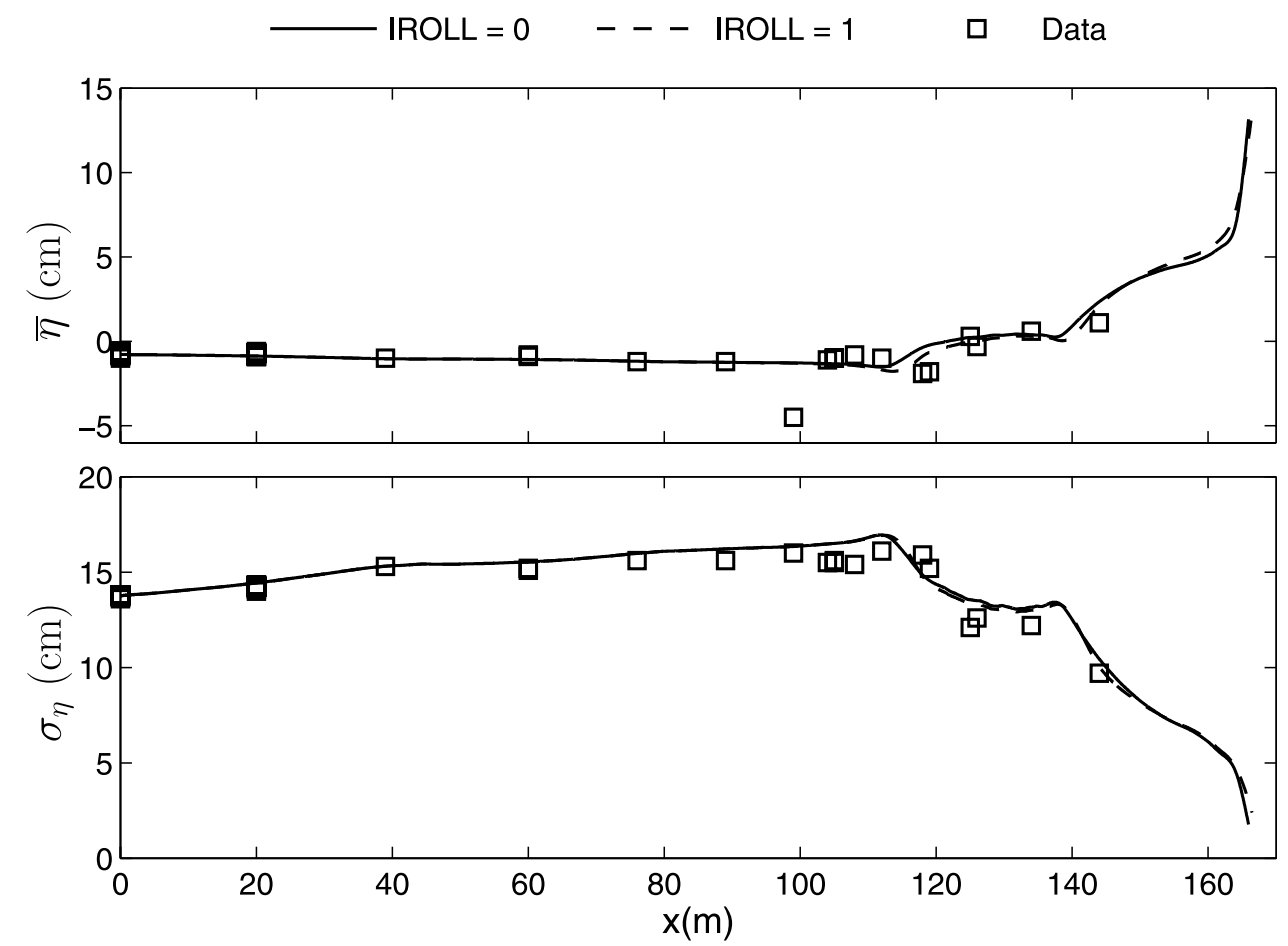

Figure 8. Measured and predicted (top) mean and (bottom) standard deviation of free surface elevation $\eta$ for test $1 \mathrm{c}$. 

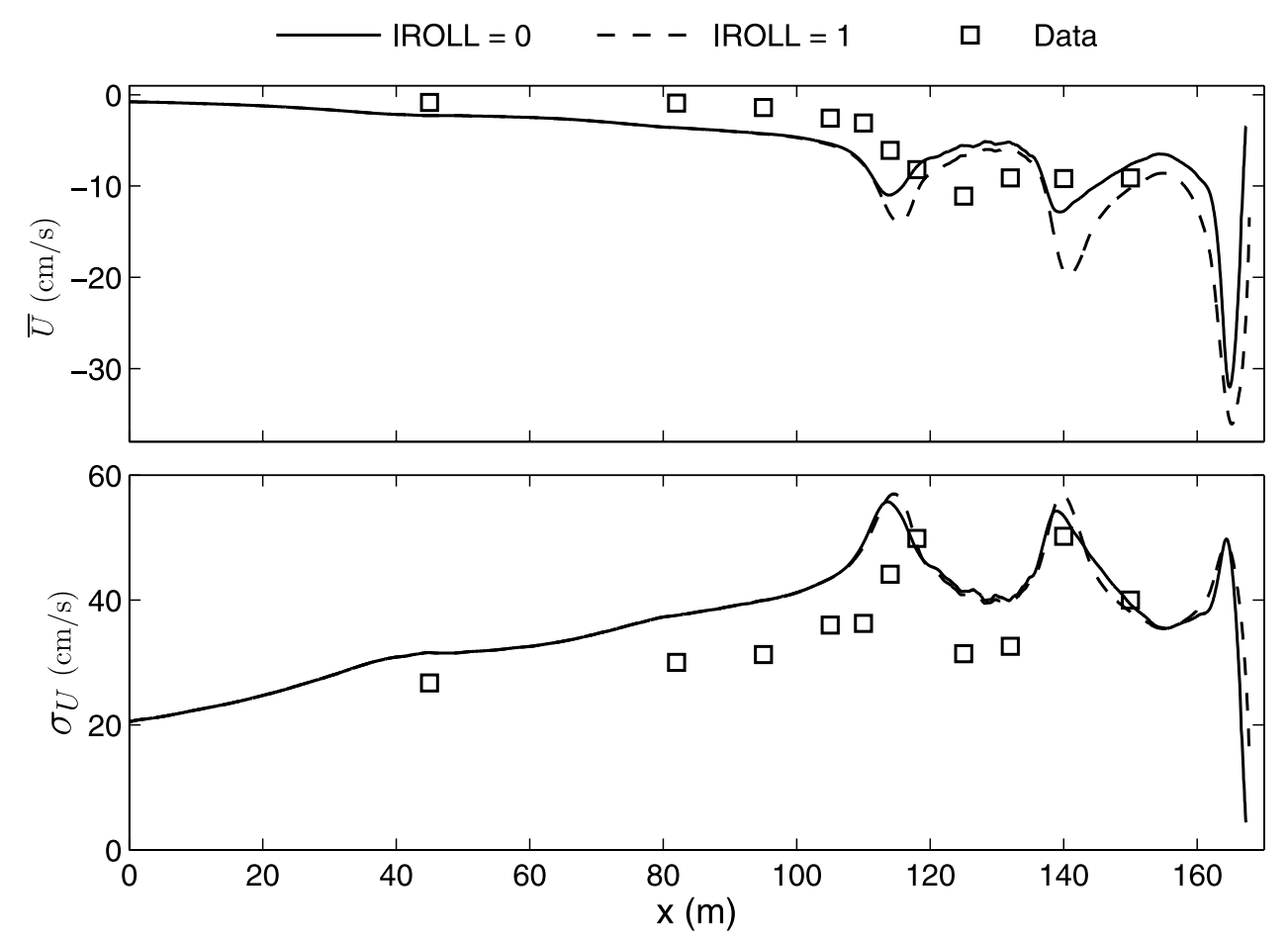

Figure 9. Measured and predicted (top) mean and (bottom) standard deviation of horizontal fluid velocity $U$ for test $1 \mathrm{c}$.

breaking waves. The agreement for $\sigma_{U}$ is better but the numerical model tends to somewhat overpredict $\sigma_{U}$. The computed increase of $-\bar{U}$ and $\sigma_{U}$ near the shoreline cannot be verified for lack of velocity data in very shallow water.
[49] Figure 10 shows the comparison of the time-averaged suspended sediment volume $V_{s}$ per unit area. The timeaveraged suspended sediment concentrations were measured at 10 elevations above $5 \mathrm{~cm}$ from the local bed. The

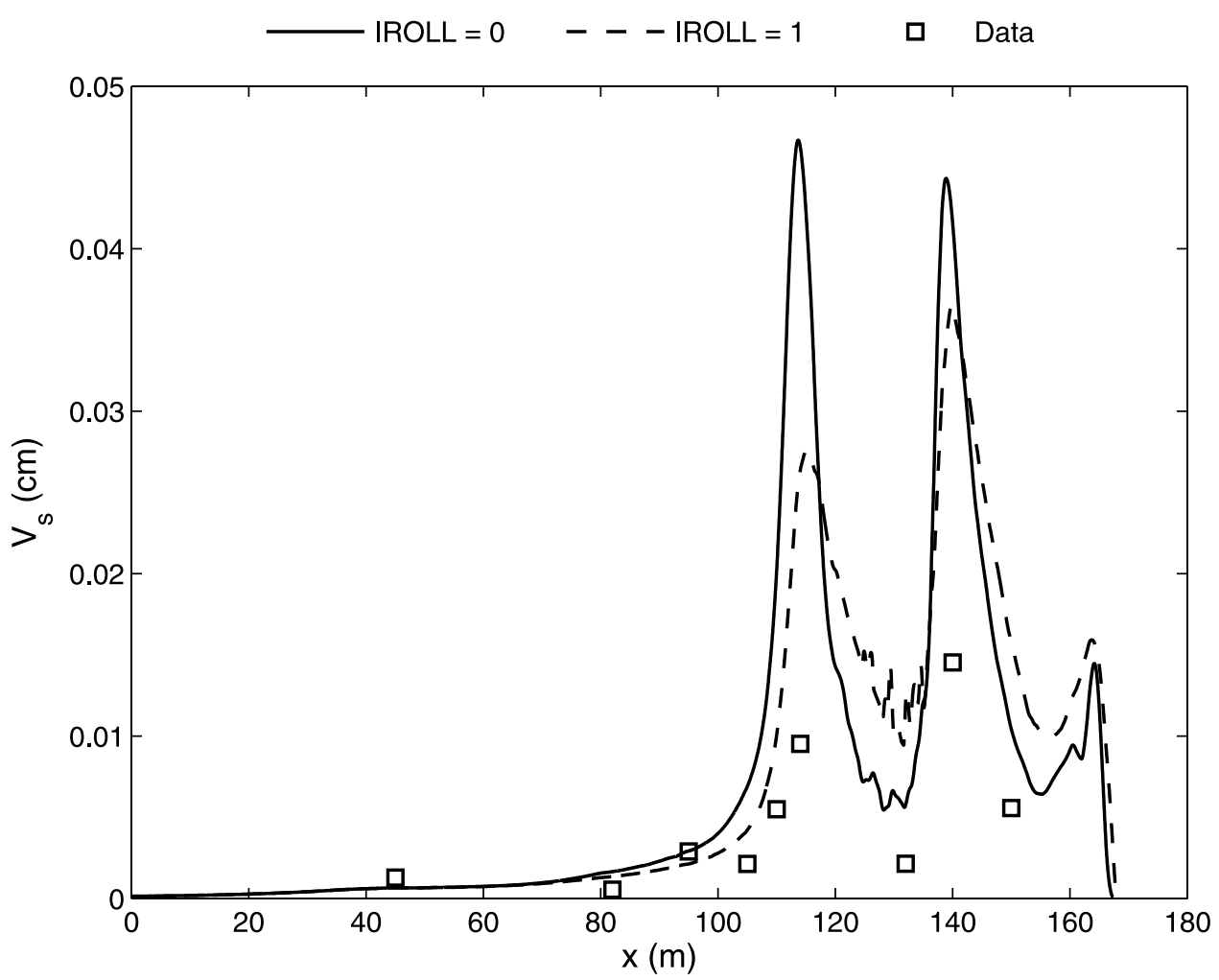

Figure 10. Measured and predicted suspended sediment volume $V_{s}$ per unit area for test $1 \mathrm{c}$. 


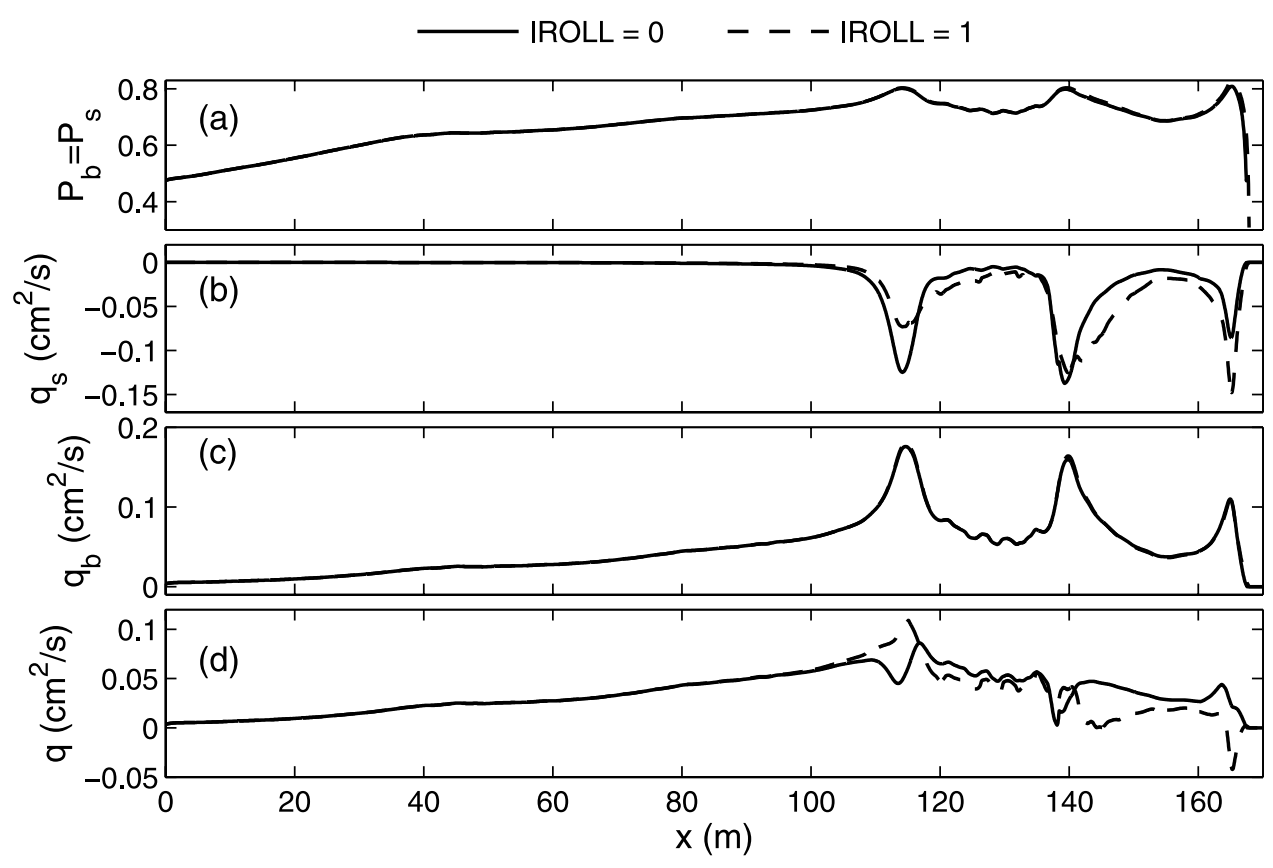

Figure 11. Predicted cross-shore variations for test 1c of (a) $P_{b}$, where $P_{s}=P_{b}$ for this test, (b) $q_{s}$, (c) $q_{b}$, and (d) $q=\left(q_{s}+q_{b}\right)$.

measured concentrations are fitted to a power-form distribution in the zone between $1 \mathrm{~cm}$ above the bed and the mean water level to obtain the vertically integrated value of $V_{s}$ in the same way as in the previous comparison by Kobayashi et al. [2005]. The roller effect causes the shoreward shift of $V_{s}$ because of the delayed energy dissipation but does not necessarily improve the agreement. The numerical model cannot predict $V_{s}$ accurately as was the case with the previous comparison.

[50] Figure 11 shows the predicted cross-shore variations of the probabilities $P_{b}$ and $P_{s}$, and the sediment transport rates $q_{s}, q_{b}$, and $q=\left(q_{b}+q_{s}\right)$ for test 1c where $P_{b}=P_{s}$ for the seven large-scale tests. In comparison to Figure 5 for the small-scale test E, the probabilities $P_{b}$ and $P_{s}$ are increased up to approximately 0.8 . The offshore suspended sediment transport rate $q_{s}$ and the onshore bed load transport rate $q_{b}$ are much larger and have an additional peak at the terrace edge of the beach profile for test $1 \mathrm{c}$. The net sediment transport rate $q$ is predicted to be onshore except in the swash zone for IROLL $=1$.

[51] The measured and predicted profile changes are compared using Figure 7. For test 1a, the measured profile change was less than about $10 \mathrm{~cm}$ after the 12-h wave action, indicating that the equilibrium profile based on equation (21) was indeed quasi-equilibrium. The computed profile changes are less than $5 \mathrm{~cm}$ except near the shoreline where the numerical model predicts about $10-\mathrm{cm}$ accretion unlike the measured profile change. For test $1 \mathrm{~b}$, the measured profile change was less than $30 \mathrm{~cm}$ after the 18 -h wave action, whereas the predicted profile changes were less than about $15 \mathrm{~cm}$. The numerical model does not predict the growth and offshore migration of the bar crest and the erosion in the bar trough sufficiently. It is noted that van Rijn et al. [2003] found it necessary to introduce the increased roughness due to ripples in the bar trough to reproduce this bar growth. For test $1 \mathrm{c}$, the measured profile change was less than $30 \mathrm{~cm}$ after the 13-h wave action. The numerical model with IROLL $=0$ and 1 predicts similar profile changes but cannot predict the measured onshore bar migration. In short, detailed profile changes including bar migration are difficult to predict accurately using the simple equations (23) and (26) with constant $a$ and $b$.

[52] In the following, the numerical model is compared with dune tests $2 \mathrm{a}, 2 \mathrm{~b}, 2 \mathrm{e}$, and $2 \mathrm{c}$ performed in sequence. The initial profile for test $2 \mathrm{a}$ was the equilibrium profile used for test 1a apart from a dune built above SWL. The wave conditions for tests $1 \mathrm{a}$ and $2 \mathrm{a}$ were approximately the same as shown in Table 3 . The wave conditions for tests $2 b$ and $2 \mathrm{e}$ corresponded to those of test $1 \mathrm{~b}$. The still water level was increased by $0.5 \mathrm{~m}$ in test $2 \mathrm{e}$ to cause significant dune erosion. The still water level was reduced to the original level in test $2 \mathrm{c}$ whose wave conditions corresponded to those of test $1 \mathrm{c}$.

[53] Figure 12 shows the measured initial and final profiles in the region of the noticeable profile changes for tests $2 \mathrm{a}, 2 \mathrm{~b}$, and $2 \mathrm{c}$ together with the predicted final profiles for IROLL $=0$ and 1 . Figure 12 can be compared with Figure 7 for tests $1 \mathrm{a}, 1 \mathrm{~b}$ and $1 \mathrm{c}$. The elevation of the dune crest was $1.8 \mathrm{~m}$ above SWL and the slope of the dune face was approximately 0.8 . The landward dune retreat of about $8 \mathrm{~m}$ from test $2 \mathrm{~b}$ to test $2 \mathrm{c}$ occurred during test $2 \mathrm{e}$. For test $2 \mathrm{a}$, the measured profile change was less than about $10 \mathrm{~cm}$ and the numerical model predicts the negligible profile changes well. For test $2 \mathrm{~b}$, the measured profile change was less than $15 \mathrm{~cm}$ apart from the minor dune erosion and steepening of the dune face. This time-averaged model cannot predict the minor dune erosion due to infrequent large wave runup. For test $2 \mathrm{c}$, the measured profile change was less than $25 \mathrm{~cm}$. The numerical model underpredicts the growth and offshore migration of the bar crest but predicts 


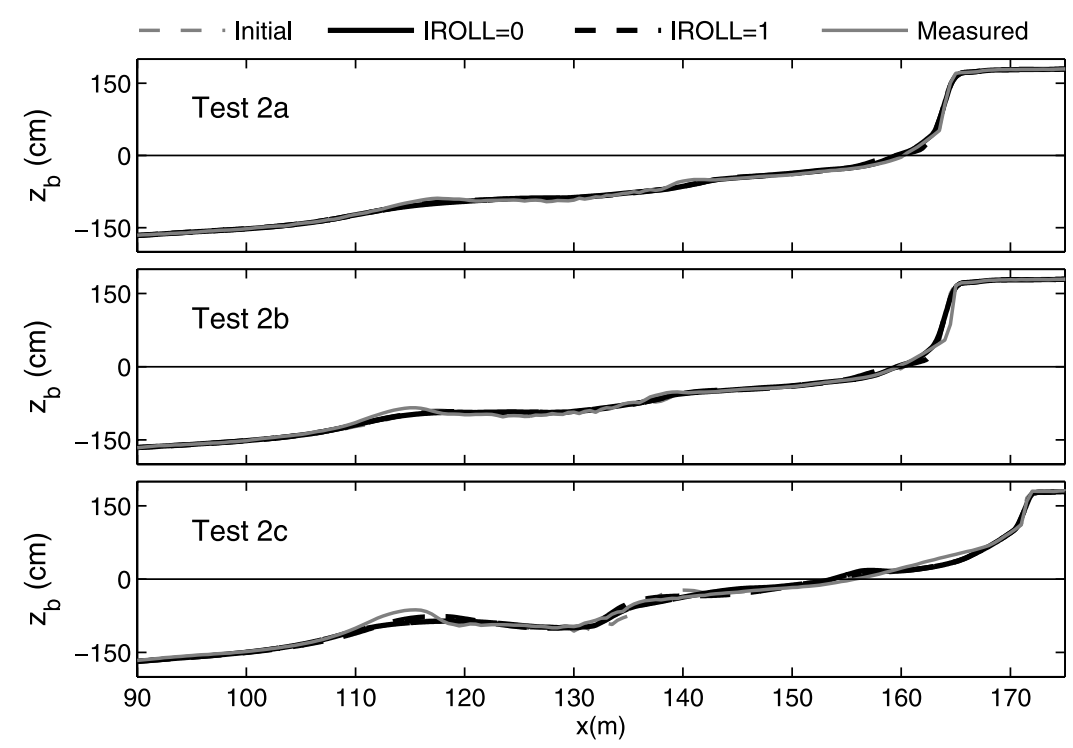

Figure 12. Measured and predicted beach profile changes at the end of large-scale tests (top) 2a, (middle) 2b, and (bottom) 2c.

the offshore migration of the terrace edge well. The numerical model predicted the accreted area above SWL but the predicted accretion does not extend far above SWL.

[54] Figure 13 shows the comparisons for test $2 \mathrm{e}$ for the suspended load parameter $a=0.2$ and 0.4 in equation (26). The still water level for test $2 \mathrm{e}$ was located $50 \mathrm{~cm}$ above $z_{b}=0$ in Figure 13. The dune erosion and resulting terrace formation on the beach in front of the eroding dune is predicted better for IROLL $=1$ because the onshore volume flux due to the roller increases the offshore return current and suspended sediment transport rate in shallow water as shown in Figures 9 and 11. The adopted value of $a=0.2$ results in the underprediction of the dune retreat by a factor of about 2. Consequently, $a$ is increased to 0.4 . The increase of the predicted dune retreat is less than the factor of 2 because the increased terrace extension on the beach reduces the wave action at the toe of the dune. In other words, the beach in front of the dune protects the dune against the incident waves. The measured dune retreat is reproduced better by the use of $a=0.8$ (not shown) but the increase of $a$ by the factor of 4 cannot be justified in the absence of velocity and concentration data in front of the eroding dune. The sediment supplied from the eroding dune could have decreased the positive correlation between the horizontal velocity and suspended sediment concentration where $a=1$ corresponds to no correlation. It is noted that the present numerical model neglects waves reflected from the steep dune face. Rakha and Kamphuis [1997]

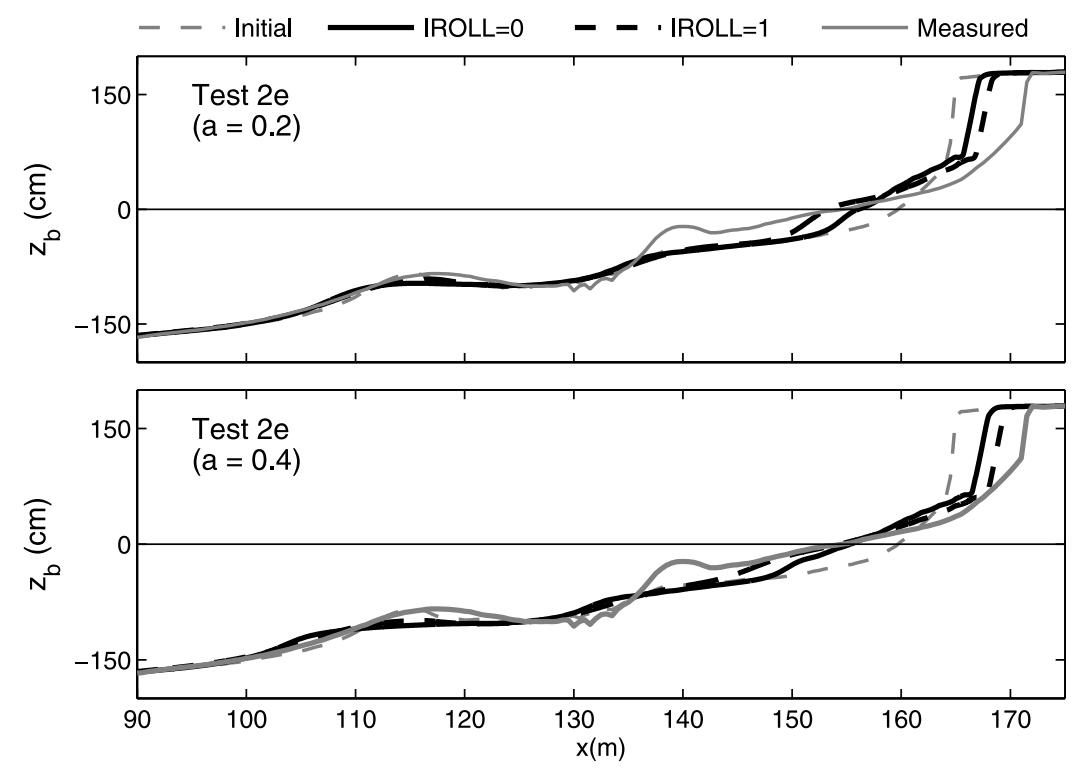

Figure 13. Measured and predicted dune profile change at the end of large-scale test 2e with (top) $a=$ 0.2 , and (bottom) $a=0.4$. 
showed experimentally and numerically that the beach profile evolution in front of a seawall was affected little by waves reflected from the seawall. As a result, the neglected reflected waves may not be the cause of the underprediction of the dune retreat in Figure 13.

\section{Conclusions}

[55] Simple formulas are developed to predict the timeaveraged rates of cross-shore suspended sediment and bed load transport in order to synthesize and simplify existing cross-shore sediment transport models. The offshore suspended sediment transport rate $q_{s}$ is expressed as $q_{s}=a \bar{U} V_{s}$ on a gently sloping beach where $\bar{U}$ is the depth-averaged return current and $V_{s}$ is the time-averaged suspended sediment volume per unit bottom area. The suspended load parameter $a$ of the order of 0.2 accounts for the reduction due to the onshore suspended sediment transport caused by the correlation of the time-varying horizontal velocity and suspended sediment concentration. The formula for $V_{s}$ is modified to include the probability of sediment suspension. The onshore bed load transport rate $q_{b}$ is expressed as $q_{b}=b P_{b} \sigma_{U}^{3} /[g(s-1)]$ where $P_{b}$ is the probability of sediment movement, $\sigma_{U}$ is the standard deviation of the horizontal velocity, $g$ is the gravitational acceleration, and $s$ is the sediment specific gravity. The bed load parameter $b$ of the order of 0.002 includes the detailed sediment dynamics neglected in this simple formula.

[56] The proposed formulas are compared with 24 tests in which net sand transport rates were measured under nonbreaking, nonlinear waves with weak currents. For these tests, $q_{s}$ is shown to be small relative to $q_{b}$ and $b$ is in the range of 0.001 to 0.004 . The formulas are also compared with 24 sheet flow tests in which net sand transport rates were measured under sinusoidal waves with strong currents. For these sinusoidal wave tests, $q_{b}$ is assumed to be in the direction of the current and the parameter $a$ for $q_{s}$ is assumed to account for the time lag of the suspended sediment. The agreement between the measured and predicted rates is within a factor of about 2 . The proposed bed load formula is simple but is also consistent with the sheet flow model for onshore bar migration by Trowbridge and Young [1989] and the energetics-based bed load formula for steady flow by Bagnold [1966] if the steady flow formula is applied in a time-averaged manner. Moreover, the condition of $\left(q_{b}+q_{s}\right)=0$ for an equilibrium profile along with additional assumptions is shown to yield the equilibrium profile popularized by Dean [1991].

[57] The effect of a steep slope is added to the proposed formulas for $q_{b}$ and $q_{s}$ to predict berm and dune erosion. The bottom slope function $G_{s}$ for $q_{b}$ on a steep upward or downward slope is proposed by extending the formula by Bagnold [1966] for steady streamflow on a downward slope. The proposed simple function $G_{S}$ depends on the local bottom slope relative to the limiting slope $\tan \phi$ which has been assumed to be 0.63 in previous studies [e.g., Bailard, 1981]. This empirical function reduces the onshore bed load transport rate $q_{b}$ on a steep upward slope and reverses the direction of $q_{b}$ on the upward slope exceeding $(\tan \phi) / 2$. The effect of a steep slope on the offshore suspended sediment transport rate $q_{s}$ is taken into account by the use of the actual slope length exposed to wave action.
An extrapolation algorithm is proposed to erode the scarped slope exceeding the limiting slope $\tan \phi$ under the action of occasional wave runup which is not predicted by this timeaveraged model. The proposed slope adjustments cannot be evaluated independently for lack of suitable data.

[58] The new formulas for $q_{s}$ and $q_{b}$ are incorporated into the time-averaged wave model by Kobayashi et al. [2005]. The continuity equation of bottom sediment is solved numerically to predict the beach profile evolution. The numerical model is compared with the three equilibrium profile tests by Kobayashi et al. [2005] and the erosion and accretion tests conducted in this study. The numerical model cannot explain all the three equilibrium profiles produced under three different spectral periods. The roller effect produces relatively large profile changes near the shoreline. The fairly subtle profile changes including bar migration of the order of $5 \mathrm{~cm}$ and $20 \mathrm{~cm}$ in the small-scale and largescale tests, respectively, are difficult to predict accurately. The comparison with two berm erosion tests conducted in a wave basin indicates that the numerical model can predict the erosion of the flat and tilted berms within a factor of about 2 . However, the alongshore variability in the wave basin was of similar magnitude.

[59] The numerical model is also compared with seven large-scale tests. The numerical model predicts the crossshore variations of $\bar{\eta}, \sigma_{\eta}$ and $\sigma_{U}$ satisfactorily where $\bar{\eta}$ and $\sigma_{\eta}$ are the mean and standard deviation of the free surface elevation $\eta$. The cross-shore variations of $\bar{U}$ and $V_{s}$ are difficult to predict accurately as was the case with the previous comparison with small-scale tests. The profile change predicted by the numerical model is in agreement for the two tests whose initial profile was based on the equilibrium profile by Dean [1991]. The numerical model cannot predict the growth and migration of the bar in the other tests. The numerical model predicts the significant dune retreat in one test within a factor of about 2 but cannot predict the minor dune erosion in another test. The roller effect increases berm and dune erosion and yields better agreement with these erosion tests. Nevertheless, the roller effect is within the uncertainty of the suspended load parameter $a$.

[60] The comparisons made in this study are limited to the median sand diameter $d_{50}$ in the range of 0.13 to $0.32 \mathrm{~mm}$ for the cases of minor profile changes, berm erosion and dune erosion. The proposed formulas for $q_{s}$ and $q_{b}$ will need to be compared with coarser sediment data and beach recovery data. These formulas will also need to be extended to obliquely incident waves with longshore currents in order to allow the comparison of the formulas with field data. However, the experiment in the wave basin suggests that the alongshore variability of sediment transport processes of berm and dune erosion may be appreciable even when the bathymetry and incident waves may appear approximately uniform alongshore. The simplicity of the proposed formulas will facilitate the calibration and verification of the formulas for engineering applications.

[61] Acknowledgments. This study was supported by the NOAA Office of Sea Grant, Department of Commerce, under grant NA85AA-DSG033 (Project SG0507 R/ETE-4) and by the U.S. Army Corps of Engineers, Coastal and Hydraulics Laboratory (MORPHOS-3D Project). The second author was supported by the Spanish Postdoctoral Scholarship MEC/FULBRIGHT. The authors would like to thank three reviewers for their thorough reviews and constructive comments. 


\section{References}

Bagnold, R. A. (1966), An approach to the sediment transport problem from general physics, U.S. Geol. Surv. Prof. Paper, 422-I, 37 pp., U.S. Government Printing Office, Washington, D. C.

Bailard, J. A. (1981), An energetics total load sediment transport model for a plane sloping beach, J. Geophys. Res., 86, 10,938-10,954

Bailard, J. A., and D. L. Inman (1981), An energetics bedload model for a plane sloping beach: Local transport, J. Geophys. Res., 86, 2035-2043.

Battjes, J. A., and M. J. F. Stive (1985), Calibration and verification of a dissipation model for random breaking waves, J. Geophys. Res., 90, 9159-9167.

Bowen, A. J. (1980), Simple models of nearshore sedimentation: Beach profiles and longshore bars, in Coastline of Canada, edited by S. B. McCann, pp. 1-11, Geol. Surv. Can., Halifax, N. S.

Calantoni, J., and J. A. Puleo (2006), Role of pressure gradients in sheet flow of coarse sediments under sawtooth waves, J. Geophys. Res., 111, C01010, doi:10.1029/2005JC002875.

Dean, R. G. (1991), Equilibrium beach profile: Characteristics and applications, J. Coastal Res., 7, 53-84.

Dean, R. G., and R. A. Dalrymple (2002), Coastal Processes with Engineering Applications, 475 pp., Cambridge Univ. Press, New York.

Doering, J. C., B. Elfrink, D. M. Hanes, and G. Ruessink (2000), Parameterization of velocity skewness under waves and its effect on cross-shore sediment transport, paper presented at 27th Coastal Engineering Conference, World Sci., Hackensack, N. J.

Dohmen-Janssen, C. M., and D. H. Hanes (2002), Sheet flow dynamics under monochromatic nonbreaking waves, J. Geophys. Res., 107(C10), 3149, doi:10.1029/2001JC001045.

Dohmen-Janssen, C. M., D. F. Kroekenstoel, W. N. Hassan, and J. S. Ribberink (2002), Phase lags in oscillatory sheet flow: Experiments and bed load modelling, Coastal Eng., 47, 295-327.

Foster, D. L., A. J. Bowen, R. A. Holman, and P. Natoo (2006), Field evidence of pressure gradient induced incipient motion, J. Geophys. Res., 111, C05004, doi:10.1029/2004JC002863.

Gallagher, E. L., S. Elgar, and R. T. Guza (1998), Observations of sand bar evolution on a natural beach, J. Geophys. Res., 103, 3203-3215.

Gallagher, E. L., E. B. Thornton, and T. P. Stanton (2003), Sand bed roughness in the nearshore, J. Geophys. Res., 108(C2), 3039, doi:10.1029/ 2001JC001081.

Guza, R. T., and E. B. Thornton (1985), Velocity moments in nearshore, J. Waterw. Port Coastal Ocean Eng., 111, 235-256.

Henderson, S. M., J. S. Allen, and P. A. Newberger (2004), Nearshore sandbar migration predicted by an eddy-diffusive boundary layer model, J. Geophys. Res., 109, C06024, doi:10.1029/2003JC002137.

Hoefel, F., and S. Elgar (2003), Wave-induced sediment transport and sandbar migration, Science, 299, 1885-1887.

Inman, D. L., M. H. S. Elwany, and S. A. Jenkins (1993), Shorerise and barberm profiles on ocean beaches, J. Geophys. Res., 98, 18,181-18,199.

Kobayashi, N., and B. D. Johnson (2001), Sand suspension, storage, advection, and settling in surf and swash zones, J. Geophys. Res., 106, $9363-9376$

Kobayashi, N., and Y. Tega (2002), Sand suspension and transport on equilibrium beach, J. Waterw. Port Coastal Ocean Eng., 128, 238-248.

Kobayashi, N., M. N. Herrman, B. D. Johnson, and M. D. Orzech (1998), Probabilistic distribution of surface elevation in surf and swash zones, J. Waterw. Port Coastal Ocean Eng., 118, 368-386.

Kobayashi, N., H. Zhao, and Y. Tega (2005), Suspended sand transport in surf zones, J. Geophys. Res., 110, C12009, doi:10.1029/2004JC002853.
Kriebel, D. L., N. C. Kraus, and M. Larson (1991), Engineering methods for predicting beach profile response, paper presented at Coastal Sediments '91 Conference, Am. Soc. Civ. Eng., Reston, Va.

Madsen, O. S., and W. D. Grant (1976), Quantitative description of sediment transport by waves, paper presented at 15th Coastal Engineering Conference, Am. Soc. Civ. Eng., Reston, Va.

Melby, J. A., and N. Kobayashi (1998), Progression and variability of damage on rubble mound breakwaters, J. Waterw. Port Coastal Ocean Eng., 124, 286-294.

Nairn, R. B., and H. N. Southgate (1993), Deterministic profile modelling of nearshore processes. Part II: Sediment transport and beach profile development, Coastal Eng., 19, 57-96.

Payo, A., N. Kobayashi, and K. Kim (2006), Beach nourishment strategies, paper presented at 30th Coastal Engineering Conference, World Sci., Hackensack, N. J.

Puleo, J. A., R. A. Beach, R. A. Holman, and J. S. Allen (2000), Swash zone sediment suspension and transport and the importance of boregenerated turbulence, J. Geophys. Res., 105, 17,021-17,044.

Rakha, K. A., and J. W. Kamphuis (1997), A morphology model for an eroding beach backed by a seawall, Coastal Eng., 30, 53-75.

Rakha, K. A., R. Deigaard, and I. Brøker (1997), A phase-resolving cross shore sediment transport model for beach profile evolution, Coastal Eng., $31,231-261$

Raubenheimer, G., R. T. Guza, S. Elgar, and N. Kobayashi (1995), Swash on a gently sloping beach, J. Geophys. Res., 100, 8751-8760.

Ribberink, J. S. (1998), Bed-load transport for steady flows and unsteady oscillatory flows, Coastal Eng., 34, 59-82.

Ribberink, J. S., and A. A. Al-Salem (1994), Sediment transport in oscillatory boundary layers in cases of rippled beds and sheet flow, J. Geophys. Res., 99, 12,707-12,727.

Roelvink, J. A., and A. J. H. M. Reniers (1995), LIP 11D delta flume experiments, Data Rep. H2130, Delft Hydraulics, Delft.

Schmied, L. D., N. Kobayashi, A. Payo, and J. A. Puleo (2006a), Crossshore sediment transport and beach profile change, Res. Rep. CACR-0603, Cent. for Appl. Coastal Res., Univ. of Delaware, Newark, Del.

Schmied, L., N. Kobayashi, J. Puleo, and A. Payo (2006b), Cross-shore suspended sand transport on beaches, paper presented at 30th Coastal Engineering Conference, World Sci., Hackensack, N. J.

Seymour, R., R. T. Guza, W. O'Reilly, and S. Elgar (2005), Rapid erosion of a small southern California beach fill, Coastal Eng., 52, 151-158.

Steetzel, H. J. (1991), A model for profile changes during storm surges, paper presented at Coastal Sediments '91 Conference, Am. Soc. Civ. Eng., Reston, Va.

Tega, Y., and N. Kobayashi (1999), Numerical modeling of overwashed dune profiles, paper presented at Coastal Sediments '99 Conference, Am. Soc. Civ. Eng., Reston, Va.

Thornton, E. B., R. T. Humiston, and W. Birkemeier (1996), Bar/trough generation on a natural beach, J. Geophys. Res., 101, 12,097-12,110.

Trowbridge, J., and D. Young (1989), Sand transport by unbroken water waves under sheet flow conditions, J. Geophys. Res., 94, 10,971-10,991. van Rijn, L. C., D. J. R. Walstra, B. Grasmeijer, J. Sutherland, S. Pan, and J. P. Sierra (2003), The predictability of cross-shore bed evolution of sandy beaches at the time scale of storms and seasons using processbased Profile models, Coastal Eng., 47, 295-327.

Williams, J. J., P. S. Bell, and P. D. Thorne (2005), Unifying large and small wave-generated ripples, J. Geophys. Res., 110, C02008, doi:10.1029/ 2004JC002513

N. Kobayashi, A. Payo, and L. Schmied, Ocean Engineering Laboratory, Center for Applied Coastal Research, University of Delaware, Academy Street, Newark, DE 19716, USA. (nk@coastal.udel.edu) 